\title{
LA DOCUMENTACIÓN PERTINENTE EN LOS DESPIDOS COLECTIVOS POR CAUSAS ECONÓMICAS, TÉCNICAS, ORGANIZATIVAS Y DE PRODUCCIÓN*
}

\author{
Ricardo Bodas Martín \\ Presidente de la Sala Social de la Audiencia Nacional
}

\section{ABSTRACT}

Resumen: El despido colectivo por causas económicas, técnicas, organizativas y de producción requiere del cumplimiento de determinados requisitos para llevarlo a cabo; requisitos que limitan las potestad empresarial en este sentido. En esta ponencia se expondrán esos requisitos y los elementos probatorios que la empresa debe aportar, todo ello desde el punto de vista de la jurisprudencia más reciente al respecto.

Palabras clave: despido colectivo, causas económicas, técnicas, organizativas y de producción, pruebas y jurisprudencia.

Abstract: The collective dismissal for economic, technical, organizational and production reasons requires the fulfillment of certain requirements to carry it out; Requirements that limit business power in this regard. This paper will outline those

* Ponencia presentada en el II Encuentro de Profesionales del Asesoramiento Laboral y Social NEGOCIACIÓN COLECTIVA Y CONTROL SINDICAL. ASPECTOS LABORALES Y ECONÓMICOS, 29 y 30 de septiembre de 2016. Facultad de Relaciones Laborales y Trabajo Social UPV-EHU (Leioa). 
requirements and the evidence that the company must provide, all from the point of view of the most recent case law in this regard.

Keywords: Collective dismissal, economic, technical, organizational and production causes, evidence and jurisprudence. 


\section{SUMARIO}

Sumario: 1. Introducción. 2. Las cargas probatorias del despido colectivo por causas económicas. 2.1. Pérdidas actualizadas. 2.2. Concurrencia de pérdidas previsibles. 2.3. La reducción de ingresos o ventas durante tres trimestres consecutivos. 3. Empresa encuadrada en grupo de empresas. 3.1. Grupo mercantil. 3.2. Grupo a efectos laborales. 3.2.1. La concurrencia de confusión patrimonial. 3.2.2. Confusión de plantillas. 3.2.3. Uso abusivo de la personalidad jurídica. 4. El debate inmediato: operaciones vinculadas y precios de mercado y requisitos para que prevalezca el interés del grupo frente al interés de las filiales y acreedores débiles, especialmente los trabajadores. 5. La documentación complementaria y su relevancia. 6. La prueba del efecto desencadenante de la causa y la pérdida de eficacia económica del contrato. 6.1. Pérdidas actualizadas. 6.2. Pérdidas previsibles. 6.3. Reducción de ingresos o ventas durante tres trimestres consecutivos. 7. La adecuación entre la intensidad de las causas y las extinciones contractuales. 8. Causas técnicas, organizativas o de producción.

\section{Introducción}

El despido colectivo no es una potestad soberana del empresario, quien está obligado, cuando tenga la intención de despedir colectivamente por causas económicas, técnicas, organizativas o de producción, a consultar previamente, en tiempo hábil, con los representantes de los trabajadores con vistas a llegar a un acuerdo (art. 2.1 Dir. 98/59/CEE y art. 51 ET), entendiéndose por tiempo hábil el que permita alcanzar los objetivos de la consulta, por lo que la aportación tardía de documentación no comportará mecánicamente la nulidad del despido (STS 24-03-2015, rec. 217/2014). —El período de consultas se constituye, de este modo, en una manifestación específica de la negociación colectiva (STS 2603-2014, rec. 158/2013 y SAN 21-07-2015, proced. 17/715), que deberá procurar necesariamente, al tratarse de objetivos mínimos, sobre las posibilidades de evitar o reducir el despido colectivo y de atenuar sus consecuencias mediante el recurso a medidas sociales de acompañamiento destinadas, en especial, a la ayuda para la readaptación o la reconversión de los trabajadores despedidos (art. 2.2 Directiva). - Dicha negociación finalista obliga por igual a empresarios y a los representantes de los trabajadores, quienes deben procurar alcanzar efectivamente los objetivos propuestos mediante la negociación de buena fe (STJUE 16-07-2009, TJUE 2009\237). 
Se trata, en todo caso, de una negociación colectiva compleja, que exige al empleador proporcionar a los representantes de los trabajadores toda la información pertinente para que el período de consultas pueda alcanzar sus fines. - Se entiende por información pertinente, a tenor con el art. 2.3 Directiva, asumida por el art. 64.1 ET, la que permita a los representantes de los trabajadores hacerse cabalmente una composición de lugar, que les permita formular propuestas constructivas en tiempo hábil (STJCE 10-09-2009, TJCE 2009 \263). - Dicha información no puede eludirse, siquiera, porque la empresa esté en proceso de liquidación (STJCE 3-03-2011, EDJ 2011/8346). - Tampoco es eludible cuando la decisión haya sido tomada por la empresa dominante (art. 2.4 Directiva y art. 51.8 ET), lo cual obligará a acreditar efectivamente que concurre una sociedad dominante, entendiéndose como tal aquella que controle a otras, concurriendo tal control cuando dicha empresa pueda imponer la política financiera y de explotación de sus filiales, a tenor con lo dispuesto en la Norma de Valoración 19.1 RD 1514/2007, de 16 de noviembre, cuya carga probatoria corresponderá a quien lo pretenda (STSJ Cataluña 15-10-2012, proced. 32/2012).

La obligación empresarial de proporcionar información pertinente a los representantes de los trabajadores se cumple, tal y como dispone el art. 64.1 ET, cuando se efectúa la transmisión de los datos necesarios para que la representación de los trabajadores tenga conocimiento preciso de una cuestión determinada y pueda proceder a su examen, sin que los trabajadores puedan imponer la aportación de cualquier documentación, salvo que acrediten su relevancia para la negociación del período de consultas (STS 27-05-2013, rec. 78/2012; SAN 1-04-2013, proced. 17/2013; SAN 24-02-2014, proced. 493/2013; SAN 4-04-2013, proced. 63/2013; SAN 30-05-2014, proced. 13/2014; SAN 12-062014, proced. 79/2014). —Dicha información habrá de versar necesariamente sobre las causas, alegadas por el empresario, así como sobre su adecuación a las medidas propuestas (SAN 21-11-2012, proced. 167/2012 y STS 25-06-2014, rec. 165/2013). - Si no se hiciera así, si la información aportada no permitiera alcanzar razonablemente los fines perseguidos por el período de consultas, la consecuencia sería la nulidad de la medida, a tenor con lo dispuesto en el art. 124.11 LRJS (STS 30-06-2011; 18-01-2012 y 23-04-2012 y SAN 7-122012, proced. 243/2012; SAN 19-12-2012, proced. 251/2012; SAN 24-022014, proced. 493/2013; SAN 28-03-2014, proced. 44/2012).

Los reproches sobre la información insuficiente aportada en el período de consultas se han convertido, especialmente en los despidos colectivos por causas económicas, en el principal factor de conflictividad en los procesos de impugnación de despidos colectivos, por lo que parece oportuno examinar con cierto detenimiento qué documentación permitirá que el período de consultas alcance sus objetivos, para lo cual abordaremos únicamente en este trabajo qué documentación económica es pertinente y cual no lo es en este tipo de despidos. 
Conviene precisar, antes que nada, que la jurisprudencia (STS 27-05-2013, rec. 78/2012 y 18-02-2014, rec. 74/2013) ha concluido que la documentación, exigida por el art. 4 RD 1483/2012, de 29 de octubre, no tiene valor «ad solemnitatem", y no toda ausencia documental por fuerza ha de llevar a la referida declaración de nulidad, sino que de tan drástica consecuencia han de excluirse —razonablemente- aquellos documentos que se revelen «intrascendentes» a los efectos que la norma persigue, consistente en proporcionar información que consienta una adecuada negociación en orden a la consecución de un posible acuerdo sobre los despidos y/o medidas paliativas. - Dicha conclusión podría hacer pensar que la documentación, contenida en el art. 4 RD 1483/2012, no es relevante por sí misma, lo que sería totalmente equivocado, puesto que su falta de aportación comportará normalmente la nulidad del despido (SAN 7-122012, proced. 243/2012 y 19-12-2012, proced. 251/2012; STS 19-11-2013, rec. 78/2013 y STS 25-02-2015, rec. 145/2014, confirma SAN 28-10-2013), salvo cuando se acredite que dicha omisión no impidió que el período de consultas alcanzara sus fines (STS 18-07-2014, rec. 313/2013), lo que sucederá normalmente cuando dicho período concluya con acuerdo (STS 19-11-2013, rec. 78/2013).

En efecto, el art. 4 del Reglamento distingue qué información debe aportarse, según se apoye la medida en la concurrencia de pérdidas actuales, previstas, o en la disminución persistente de su nivel de ingresos ordinarios o ventas, entendiéndose como tal cuando se acredite que en tres trimestres consecutivos el nivel de ingresos ordinarios o ventas de cada trimestre es inferior al registrado en el mismo trimestre del año anterior y lo hace de manera perentoria, puesto que utiliza expresiones inequívocas, tales como «deberá aportar»o «deberá informar", lo cual nos permite concluir que el empresario es deudor de dichas informaciones, que serán normalmente relevantes para acreditar los distintos supuestos de situación económica negativa, listados en el art. 51.1 ET. - El apartado quinto del precepto examinado regula, a continuación, qué documentación deberá aportarse por los grupos de empresa, distinguiendo aquellos que están obligados a la consolidación de sus cuentas de quienes no lo están, correspondiéndoles la carga de la prueba de dicha exención (STSJ Madrid 2-02-2015, rec. 872/2014).

El empresario está obligado, por tanto, a aportar a los representantes de los trabajadores una memoria, que acredite los resultados de la empresa de los que se desprenda que está en situación económica negativa, que incluirá todos los documentos que estime conveniente y en particular los listados en el art. 4 del Reglamento, sin que baste una memoria genérica (STSJ Madrid 30-05-2012, rec. 17/2012 y STS 19-11-2013, rec. 78/2013), porque el objetivo de la memoria es acreditar la concurrencia de la causa económica y acreditar significa "probar su existencia o realidad). - La memoria deberá identificar la adecuación entre las causas y la pérdida de eficacia económica de los contratos, con arreglo a téc- 
nicas de ponderación, entendiéndose como tales la razonabilidad y proporcionalidad de la medida (SAN 21-11-2012, proced. 167/2012), habiéndose admitido por la jurisprudencia, que el control judicial pasa, sin que ello signifique control de oportunidad o exigencia de optimización de la medida empresarial, por constatar la idoneidad y razonabilidad de la medida, lo cual obligará a demostrar que el despido colectivo se ajusta a la intensidad de la causa (STS 27-01-2014, rec. 100/2013, confirma SAN 22-11-2012). —De hecho, la jurisprudencia más reciente ha exigido que la decisión, sobre si concurren las causas justificadoras de los despidos, obliga a hacer un juicio de adecuación, razonabilidad y proporcionalidad (en términos de los sacrificios de las partes en presencia) de las concretas medidas extintivas adoptadas (STS 25-06-2014, rec. 165/2013).

La documentación deberá aportarse en tiempo hábil, entendiéndose como tal el necesario para que los representantes de los trabajadores puedan comprenderla adecuadamente y proponer propuestas constructivas, por lo que se ha entendido que no se vulneró dicho derecho cuando se aportaron las cuentas anuales al día siguiente de iniciarse el período de consultas (SAN 11-11-2013, proced. 288/2013). - Es habitual, que el empresario aporte documentación durante el período de consultas, bien porque no disponía de ella a su inicio, bien porque se le exigió en la negociación, sin que dicha aportación sea extemporánea, siempre que permita alcanzar los fines del período de consultas.

\section{Las cargas probatorias del despido colectivo por causas económicas}

Como se señaló más arriba, el empresario está obligado a demostrar la concurrencia de situación económica negativa en la empresa en su conjunto, que es la causa desencadenante, que producirá como efecto el despido colectivo, siempre que pruebe la conexión de adecuación. - El art. 4.2 RD 1483/2012 dispone que para la acreditación de los resultados alegados por la empresa, el empresario podrá acompañar toda la documentación que a su derecho convenga, aunque deberá apoyarla, en todo caso, en la documentación reglamentaria, que dependerá de si se trata de pérdidas actualizadas, previsión de pérdidas o reducción persistente de ingresos y ventas. - Conviene precisar, antes que nada, que la jurisprudencia ${ }^{1}$ ha concluido que la documentación, exigida por el art. $4 \mathrm{RD}$ $1483 / 2012$, de 29 de octubre, no tiene valor «ad solemnitatem", y no toda ausencia documental por fuerza ha de llevar a la referida declaración de nulidad, sino que de tan drástica consecuencia han de excluirse — razonablementeaquellos documentos que se revelen «intrascendentes» a los efectos que la norma persigue, consistente en proporcionar información que consienta una adecuada negociación en orden a la consecución de un posible acuerdo sobre los despidos

1 STS 27-05-2013, rec. 78/2012 y 18-02-2014, rec. 74/2013. 
y/o medidas paliativas. - Dicha conclusión podría hacer pensar que la documentación, contenida en el art. 4 RD 1483/2012, no es relevante por sí misma, lo que sería totalmente equivocado, puesto que su falta de aportación comportará normalmente la nulidad del despido ${ }^{2}$, salvo cuando se acredite que dicha omisión no impidió que el período de consultas alcanzara sus fines ${ }^{3}$, lo que sucederá normalmente cuando dicho período concluya con acuerdo ${ }^{4}$.

\subsection{Pérdidas actualizadas}

Cuando la situación económica negativa derive de la concurrencia de pérdidas actuales, el empresario deberá aportar obligatoriamente las cuentas anuales de los dos últimos ejercicios económicos completos, integradas por balance de situación, cuentas de pérdidas y ganancias, estado de cambios en el patrimonio neto, estado de flujos de efectivos, memoria del ejercicio e informe de gestión. -No obstante, cuando concurran las circunstancias previstas en los arts. 257 y 258 RDL 1/2010, de 2 de julio, sobre sociedades de capital, deberá aportarse la cuenta de pérdidas y ganancias abreviada y balance y estado de cambios en el patrimonio neto abreviados. - Las cuentas deberán presentarse debidamente auditadas en el caso de empresas obligadas a realizar auditorias, salvo que la empresa no esté sujeta a tal obligación, en cuyo caso la representación de la empresa deberá aportar declaración sobre exención de la auditoria, correspondiéndole, en todo caso, la carga de la prueba sobre dicha exención, si bien se ha entendido que no constituye causa de nulidad que no se aportaran las cuentas auditadas al inicio del período de consultas, cuando se acreditó posteriormente que las auditadas coincidían con las provisionales ${ }^{5}$, habiéndose validado que no se aportaran las cuentas auditadas, porque no había vencido el plazo para su aprobación por la Junta General ${ }^{6}$. - Por el contrario, si en el período de consultas no se aportaron las cuentas auditadas, porque no se había cumplido el plazo legal, debieron aportarse al acto del juicio, cuando ya estaban auditadas, porque se corre el riesgo de que no se consideren creíbles las provisionales ${ }^{7}$. - La falta de aportación de las cuentas citadas comportará la nulidad del despido ${ }^{8}$. - Si las cuentas anuales no fueron aprobadas, ni depositadas en el Registro Mercantil, deberá aportarse otra información fiscal o contable, por cuanto las citadas cuentas carecerán de fiabilidad ${ }^{9}$.

2 SAN 7-12-2012, proced. 243/2012 y 19-12-2012, proced. 251/2012; STS 19-11-2013, rec. 78/2013 y STS 25-02-2015, rec. 145/2014, confirma SAN 28-10-2013.

3 STS 18-07-2014, rec. 313/2013.

4 STS 19-11-2013, rec. 78/2013; STS 25-06-2014, rec. 165/2014; SAN 13-11-2015, proced. 257/2015 y SAN 18-01-2016, proced. 311/2015.

5 STS 20-11-2014, rec. 114/2014.

6 STSJ Asturias 20-09-2013, rec. 1379/2013.

7 SAN 26-01-2015, proced. 205/2014.

8 STSJ Navarra 13-12-2013, rec. 226/2013.

9 STSJ Valladolid 12-03-2015, rec. 12/2014. 
Aunque algún sector de la doctrina judicial ha defendido que el informe de auditoria tiene presunción de certeza ${ }^{10}$, lo cierto es que en el RDL 1/2011, de 1 de julio, por el que se aprobó el texto refundido de Auditoria de Cuentas, no contemplaba dicha presunción. - No obstante, la auditoria de cuentas tiene por objeto verificar dichas cuentas a efectos de dictaminar si expresan la imagen fiel del patrimonio, de la situación financiera y de los resultados de la entidad auditada, de acuerdo con el marco normativo de información financiera que resulte de aplicación; también comprenderá, en su caso, la verificación de la concordancia del informe de gestión con dichas cuentas, conforme se dispone en el art. 1.3 de la norma citada, lo que le proporciona el crédito que le da el auditor, cuyas conclusiones pueden objetarse, como no podría ser de otro modo, para lo que sería preciso la prueba de una infracción significativa de la normativa contable con quebrantamiento del principio de imagen fiel establecido en la misma ${ }^{11}$, especialmente cuando el perito de la RLT se limita a cuestionar las cuentas auditadas, porque no dispuso de documentación para constatar su veracidad, que no se consideró pertinente ${ }^{12}$. - Lo cierto es que el crédito de la auditoria dependerá de profesionalidad, objetividad e independencia de sus autores, quienes están sometidos a un régimen de incompatibilidades importante regulada en los arts. 12 a 19 del RDL 1/2011, de 1 de julio, que aprueba el texto refundido de la ley de auditoria de cuentas y deberá ajustarse a los parámetros exigidos por el art. 3 de la norma citada, así como en los arts. 14 a 20 de la Ley 22/2015, de 20 de julio, de auditoria de cuentas, que entrará completamente en vigor el 17-06-2016, sin que ninguna de las normas citadas reconozca al informe de auditoria presunción «iuris tantum», exigiéndose, por el contrario, en el art. 13 de la última norma, escepticismo profesional a los auditores, entendiéndose por escepticismo la actitud que implica mantener siempre una mente inquisitiva y especial alerta ante cualquier circunstancia que pueda indicar una posible incorrección en las cuentas anuales auditadas, debida a error o fraude, y examinar de forma crítica las conclusiones de auditoria, lo cual supone reconocer la posibilidad de que existan incorrecciones materiales en las cuentas anuales objeto de auditoria, incluyendo fraudes o errores, sea cual fuere la experiencia anterior del auditor de cuentas en relación con la honestidad e integridad de los responsables de la administración y de los directivos de la entidad auditada. Por consiguiente, cuando se debata la certeza de las cuentas auditadas, no bastará con la simple utilización de reglas estereotipadas, como la afirmación de que las transferencias se han realizado con arreglo a criterios de mercado, sino que tendrá que acreditarse que se han utilizado criterios de medición de general aceptación ${ }^{13}$.

\footnotetext{
10 STSJ Cataluña 25-05-2009, rec. 1766/2008.

11 STSJ Cataluña 25-5-09, Rec 1766/08.

12 SAN 13-11-2015, proced. 257/15.

13 SAN 28-03-2014, proced. 499/2013.
} 
Conviene precisar aquí, que las cuentas anuales, exigidas por el art. 4.2 del Reglamento, conectan con la información anual debida por el empresario a los representantes de los trabajadores (art. 64.4 ET), puesto que coincide con los derechos informativos de los socios, que es uno de sus derechos básicos de los mismos ${ }^{14}$. - De este modo, si el empresario ha cumplido regularmente dicho deber informativo, lo que habrá permitido a los representantes de los trabajadores examinar rigurosa y sistemáticamente dicha información, se dinamizará el período de consultas, puesto que los representantes de los trabajadores tendrán cumplido conocimiento de la evolución económica de la empresa y podrán precisar con más agilidad qué aclaraciones necesitan, para articular, a continuación, propuestas constructivas.

Deberán aportarse, así mismo, las cuentas provisionales al inicio del período de consultas ${ }^{15}$, entendiéndose como tales las reguladas en el art. 254 RDL 1/2010, de 7 de julio (balance, cuenta de pérdidas y ganancias, estado que refleje el patrimonio neto y flujo de efectivos), descartándose la obligación de aportar la memoria, porque la finalidad del documento se suple con la memoria del propio despido colectivo ${ }^{16}$. - Dichas cuentas deberán aportarse al momento de iniciarse el período de consultas, salvo que se pruebe la imposibilidad de hacerlo, lo cual corresponderá al empleador ${ }^{17}$, no pudiendo olvidarse que el empresario está obligado a transcribir en el libro de inventarios y cuentas, al menos trimestralmente, las sumas y saldos de los balances de comprobación, a tenor con lo dispuesto en el art. 28.1 C.Co., donde deben registrarse todos los asientos contables con arreglo al Plan General de Contabilidad, de manera que no hay razón, en principio, para que no se puedan aportar las cuentas provisionales, que se correspondan con dichos asientos, al inicio del período de consultas. - En cualquier caso, la aportación incompleta de las cuentas provisionales no provocará la nulidad del despido, cuando las aportadas no fueron discutidas por la comisión social ${ }^{18}$, o cuando se aportaron únicamente las cuentas provisionales de pérdidas y ganancias correspondientes al mes de enero, fecha de inicio del período de consultas, por tratarse de un período de escasa influencia para valorar la situación de la empresa ${ }^{19}$, ni tampoco por la falta de firma de las cuentas provisionales, especialmente si no se exigió la firma durante el período de consultas ${ }^{20}$, pero si cuando no se aportaron firmadas sin justificación alguna ${ }^{21}$. - Destacar, por otro lado, que no es

\footnotetext{
14 STS, Sala Civil 24-11-2011, rec. 1851/2007.

15 STSJ Madrid 24-04-2013, rec. 1159/2013 y SAN 22-10-2013, proced. 327/2013.

16 SAN 28-03-2014, proced. 499/2013 y STS 20-10-2015, rec. 272/2014.

17 SAN 28-03-2014, proced. 42/2014.

18 SAN 26-05-2014, rec. 25/2014.

19 SAN 15-04-2015, proced. 180/2013.

20 SAN 19-03-2013, proced. 20/2013.

21 SAN 28-03-2014, proced. 44/2012.
} 
exigible auditar las cuentas provisionales por su propia naturaleza ${ }^{22}$. - Finalmente, cuando no se aporten las cuentas provisionales completas procederá la nulidad del despido ${ }^{23}$.

Las pérdidas actualizadas se asocian a la cuenta de pérdidas y ganancias, en la que se refleja el resultado del ejercicio, concurriendo situación económica negativa, cuando los resultados son negativos ${ }^{24}$, lo cual sucederá cuando se acreditan pérdidas en los tres ejercicios precedentes y en el primer trimestre del año en que se promueve el despido colectivo ${ }^{25}$, sin que sea relevante una mejora circunstancial en el período inmediato al cese cuando las pérdidas anteriores son muy cuantiosas ${ }^{26}$.

La existencia de reservas voluntarias no contradice mecánicamente la concurrencia de situación económica negativa, puesto que son un valor contable que refleja la capacidad de financiación de la empresa y puede tener múltiples destinos, como pudiera ser el pago de deudas de la empresa ${ }^{27}$. - Cuando se dispone de ellas para repartir dividendos se ha considerado que no concurre situación económica negativa ${ }^{28}$, aunque se ha admitido la justificación del despido, aun cuando la empresa decidiera repartir dividendos con cargo a reservas voluntarias, por cuanto derivaban de ejercicios anteriores ${ }^{29}$.

Las pérdidas actualizadas pueden concurrir con la reducción sostenida de ventas, que es la que las provoca ${ }^{30}$ y también con pérdidas actuales, contracción de la demanda, subactividad y distribución ineficiente de la plantilla ${ }^{31}$.

La carga de la prueba de las pérdidas actualizadas, como se anticipó más arriba, corresponde a la empresa, que no prosperará cuando lo basa en cuentas no fiables ${ }^{32}$. Tampoco, cuando la empresa las basó en unas declaraciones fiscales

22 SAN 30-05-2014, proced. 13/2014.

23 SAN 22-10-2013, proced. 327/2013; STSJ Asturias 27-12-2013, rec. 2075/2013 y STSJ Madrid 24-04-2013, rec. 1159/2013.

24 TS 12-6-12, Rec 3638/11; TS 23-1-07, Rec 641/05RJ 1910EDJ 8713) y habilitará normalmente la justificación de la medida, siempre que las pérdidas acreditadas permitan constatar que los contratos, que se pretenden extinguir, han perdido su contenido económico para la empresa (SAN 9-02-2014, proced. 241/14; STS 25-03 y 20-05-2015, rec. 395/14 y rec. 283/14.

25 SAN 4-12-2014, proced. 247/14 y SAN 9-12-2014, proced. 241/2014.

26 STSJ Murcia 3-07-2015, rec. 148/15; STSJ Baleares 27-03-2015, rec. 338/14.

27 TSJ Castilla-La Mancha 16-9-11, Rec 796/11 y TSJ Castilla-La Mancha 23-9-11, Rec $842 / 11$.

28 STSJ Madrid 1-06-2015, rec. 767/14.

29 STS 14-10-2015, rec. 243/13, confirma SAN 15-02-2013.

30 STS 28-02-2014, rec. 27/2014 ; STS 18-03-2014, rec. 125/2013 y STS 21-04-2015, rec. $357 / 14$.

31 SAN 8-07-2013, proced. 180/2013.

32 STSJ Valladolid 12-03-2015, rec. 12/2014. 
no acreditadas ${ }^{33}$. Ni cuando se acredita que el resultado neto de la empresa ha mejorado sustancialmente con respecto a los dos ańos precedentes ${ }^{34}$.

Los resultados económicos desfavorables que colocan a la empresa en una situación económica negativa con virtualidad extintiva son los que, por su volumen, en proporción a la cifra total del negocio, y por su carácter, acreditan la pérdida de eficacia de los $\operatorname{contratos}^{35}$, sin que sea suficiente la existencia de pérdidas nimias, o de escasa significación, o meramente puntuales, episódicas, circunstanciales o coyunturales ${ }^{36}$, determinantes, en su caso, de las correspondientes medidas de flexibilidad interna ${ }^{37}$. Por el contrario, si se acreditan pérdidas sostenidas en varios ejercicios, que alcanzaron 130.933,57 euros en el mes siguiente a la promoción de medidas de flexibilidad interna, se concluye la existencia de situación económica negativa ${ }^{38}$. - Del mismo modo, se ha declarado ajustado a derecho el despido colectivo, al existir pérdidas millonarias y desmesuradamente crecientes en los dos últimos ejercicios e importantes valores negativos de rentabilidad bruta: la obtención de importante ayuda pública para reflotar la entidad bancaria, sin la cual no hubiera podido seguir operando, no hacer desaparecer las causas sino que el expediente de regulación de empleo viene a justificar esa financiación y a garantizar que las causas de la misma no se iba a mantener con el efecto pernicioso de inutilidad de la propia ayuda ${ }^{39}$. - Por el contrario, cuando la empresa acredita pérdidas cuantiosas y reiteradas en el tiempo, asociadas a la existencia de deudas acumuladas, la falta de liquidez, la disminución del volumen de negocio, la insuficiencia de los recursos patrimoniales, la crisis del sector, las adversas previsiones de futuro, existirá causa económica negativa, que desencadenará la medida extintiva ${ }^{40}$, incluso cuando se

33 STSJ Madrid 13-04-2015, rec. 41/15.

34 STSJ Madrid 23-03-2015, rec. 1012/14.

35 SAN 26-04-2013, proced. 29/2013.

36 TSJ Madrid 5-12-13, Rec 1620/13), o cuando la empresa no prueba la concurrencia de causas (STSJ Las Palmas 18-12-2014, rec. 1175/14 y STSJ Castilla la Mancha 22-01-2015, rec. $1421 / 14)$.

37 TSJ País Vasco 9-7-13, Proc 14/13.

38 STSJ Las Palmas 27-02-2015, rec. 1388/14.

39 STS 18-07-2014, rec. 288/13.

40 TS 10-12-13, Rec 549/13; AN 21-11-13, Proc 322/13; AN11-7-13, Proc181/13; AN 4-7-13, Proc169/13; AN 20-5-13, Proc108/13; AN 26-4-13, Proc 29/13; AN 25-3-13, Proc 324/12; AN 21-11-12, Proc 167/12; AN 28-9-12, Proc152/12; TSJ Madrid 25-6-13, Proc 1377/13; TSJ Aragón 11-6-13, Proc 209/13; TSJ Aragón14-1-13, Rollo 715/12; TSJ Aragón1012-12, Proc 527/12; TSJ Valladolid 27-5-13, Proc 8/13; TSJ Málaga 23-5-13, Proc 4/13; TSJ Cataluńa 19-12-12, Proc 36/12; TSJ País Vasco 18-12-12, Proc 24/12; TSJ Extremadura 25-10-12, Proc 4/12; TSJ Sevilla 11-10-12, Proc 4/12; TSJ Cantabria 26-9-12, Proc 2/12; SAN 8-07-2013, proced. 180/13; SAN 26-10-2013, proced. 284/13; SAN 18-11-2013, proced. 338/13; SAN 19-11-2013, proced. 293/13; SAN 10-12-2013, proced. 333/13; SAN 10-03-2014, proced. 285/13; SAN 1605-2014, proced. 500/13; SAN 9-07-2014, proced. 463/13; SAN 4-02-2014, proced. 247/14; SAN 9-02-2014, proced. 241/14; STS 17-07-2014, rec. 79/14; STSJ Murcia 22-02-2015, rec. 900/14 y STS 16-06-2015, rec. 283/14. 
ha producido resultado positivo en un ejercicio, que no equilibra las pérdidas de los precedentes $^{41}$.

Se entiende que la verdadera situación económico-financiera de la empresa la da el resultado neto que arroja la cuenta de pérdidas y ganancias, no pudiendo valorarse a partir de otros datos como el EBITDA que al igual que otras herramientas contables utilizadas en la gestión, control o seguimiento de una sociedad, como el margen bruto, el resultado de la explotación y el resultado operativo, sólo facilitan resultados parciales ${ }^{42}$, de manera que puede concurrir situación económica negativa, aunque el EBITDA del ejercicio fuera positivo, cuando se demuestra que no lo fue suficientemente para enjugar las graves pérdidas existentes ${ }^{43}$. - Consiguientemente, cuando la empresa ha reducido geométricamente su cifra neta de negocio, así como sus resultados de explotación, presentado unas pérdidas muy relevantes desde 2009 a 2013, que han continuado dicha evolución en el primer trimestre de 2014, encontrándose en una situación económica claramente negativa, que justifica razonable y proporcionadamente las extinciones pactadas, que redujeron sustancialmente el número inicial ${ }^{44}$, así como de acreditarse pérdidas muy relevantes, originadas en la reducción de la cifra de negocios por falta de ventas ${ }^{45}$, o pérdidas millonarias crecientes, causadas por serios desajustes productivos ${ }^{46}$, o pérdidas acumuladas de más de 60 millones de euros y una previsión de continuidad de resultados negativos en $2012 / 13^{47}$ y también las pérdidas millonarias, unidas a un descenso significativo de la demanda hotelera ${ }^{48}$, o cuando la fundación no es capaz de salir de los números rojos, pese a las subvenciones de sus patronos, que se encontraban en quiebra ${ }^{49}$, así como en empresa, que ha recibido múltiples apoyos del grupo mercantil en que se integra que acredita pérdidas millonarias con un gasto de personal, que supera el $77,9 \%$ de los gastos totales de la empresa ${ }^{50}$.

No pueden excluirse, para el cómputo de las pérdidas, los denominados "gastos no recurrentes» consignados en las cuentas, que reflejan aquellos que no se reiterarán en el ejercicio siguiente, como p.e. los asociados a un centro de trabajo que se cierra, pues no se trata de partidas extraordinarias sino ordi-

41 STS 22-12-2014, rec. 147/14.

42 TSJ Asturias 18-6-10, EDJ 148018; SAN 12-12-2013, proced. 237/13 y STS 23-10-2015, rec. $169 / 14$.

43 SAN 28-10-2013, proced. 228/2013.

44 SAN 4-12-2014, proced. 247/2014.

45 STS 25-02-2015, rec. 145/2014 y SAN 22-05-2015, proced. 401/2013.

46 SAN 13-11-2015, proced. 257/2015.

47 STS 18-02-2014, rec. 96/13.

48 STS 22-09-2014, rec. 305/2013.

49 STS 23-09-2014, rec. 52/2014.

50 STS 25-02-2015, rec. 145/2014. 
narias, que han de ser tenidas en cuenta a la hora de determinar los resultados del ejercicio ${ }^{51}$. - Así, se ha admitido también la situación económica negativa, aunque se acreditaran gastos "de naturaleza no recurrente", comprensivos de gastos de personal, otros gastos de explotación y gastos financieros, si bien en concurrencia con causa productiva al haber quedado acreditado la importante disminución del número de toneladas facturadas, la caída de la facturación en un $8 \%$ y un descenso del $16 \%$ en la cifra de negocio, habiéndose acreditado por la empresa que esta es la última de una serie de acciones de reestructuración y reducción de gastos, incluyendo flexibilidad interna; a pesar de lo cual no han conseguido revertir la situación negativa, suponiendo la partida de gastos de personal nada menos que la mitad del margen de rentabilidad de la empresa ${ }^{52}$.

\subsection{Concurrencia de pérdidas previsibles}

Cuando la situación económica negativa se base en una previsión de pérdidas, el empresario, además de aportar la documentación ya citada, deberá informar de los criterios utilizados para su estimación, para lo cual deberá presentar un informe técnico sobre el volumen y el carácter permanente o transitorio de esa previsión de pérdidas basado en datos obtenidos a través de las cuentas anuales, de los datos del sector al que pertenece la empresa, de la evolución del mercado y de la posición de la empresa en el mismo o de cualesquiera otros que puedan acreditar esta previsión. - La jurisprudencia ha subrayado que el informe técnico se valorará con arreglo a criterios de sana crítica, puesto que se trata de prueba de libre apreciación ${ }^{53}$. - Como vemos, dicha información reproduce esencialmente la información, que el empresario debe trimestralmente al comité de empresa (art. 64.2 ET), de manera que, si cumplió dicha obligación informativa, facilitará la negociación del período de consultas, por cuanto los representantes de los trabajadores dispondrán de herramientas suficientes para comprender la evolución negativa de la empresa y les permitirá realizar propuestas constructivas de manera ordenada.

La doctrina judicial ha mantenido que, si se pretende acreditar pérdidas previsibles, deberá aportarse la misma documentación que en los supuestos de pérdidas actualizadas; los criterios utilizados e informe técnico, entendiéndose que la demostración de pérdidas previsibles exige una perfecta acreditación de hechos indiciarios de los que se pueda inferir, racionalmente y con clara probabilidad, la existencia de pérdidas en el futuro que justifiquen la extinción del contrato de trabajo ${ }^{54}$, habiéndose mantenido, por ello, que la previsión de pérdi-

\footnotetext{
51 SAN 30-7-13, Proc 212/13.

52 STS 22-09-2014, rec. 27/14.

53 STS 28-01-2015.

54 STSJ Rioja 27-02-2012, rec. 18/2012.
} 
das como causa justificativa obliga a una prueba exigente para su acreditación ${ }^{55}$. -El informe técnico puede ser interno o externo y es dudoso que pueda integrarse en la memoria, puesto que el art. 4.4 Reglamento lo distingue claramente de la memoria ${ }^{56}$. - Se ha admitido que, si la empresa perdió todos sus clientes, concurrirán necesariamente pérdidas futuras ${ }^{57}$.

Aunque el art. 51.1 identifica como situación económica negativa a la previsión de pérdidas, que se constituye, de este modo, en un supuesto autónomo para la extinción colectiva de contratos de trabajo, se asocia normalmente con pérdidas ya actualizadas o con reducciones persistentes de ingresos y ventas, que conducirán normalmente a provocar pérdidas futuras ${ }^{58}$. —Así, se ha admitido la previsión de pérdidas, cuando se constata que la disminución continuada de la facturación arrojará pérdidas futuras ${ }^{59}$, así como la pérdida de la contrata principal de la empresa ${ }^{60}$ y también cuando la pervivencia o acentuación de las causas de las pérdidas ya actualizadas permiten presumir que continuarán produciéndose en el futuro ${ }^{61}$. - Se ha asociado, del mismo modo, a la reducción de ingresos y ventas en tres trimestres consecutivos, que permitan presumir la producción inmediata de pérdidas ${ }^{62}$, entendiéndose, que se actualizarán las pérdidas en el futuro, cuando se acredita la pérdida del cliente principal de la empresa ${ }^{63}$. - Se ha admitido finalmente que la reducción continuada de beneficios constituye por sí situación económica negativa ${ }^{64}$, que puede asociarse con la previsión de pérdidas ${ }^{65}$ y se ha admitido también que la previsión de reducción de ingresos constituye situación económica negativa ${ }^{66}$.

\subsection{La reducción de ingresos o ventas durante tres trimestres consecutivos}

Cuando la situación económica negativa consista en la disminución persistente del nivel de ingresos o ventas, el empresario deberá aportar, además de la documentación prevista para pérdidas actualizadas, la documentación fiscal o contable acreditativa de la disminución persistente del nivel de ingresos ordinarios o ventas durante, al menos, los tres trimestres consecutivos inmediatamente anteriores a la fecha de la comunicación de inicio del procedimiento de despido

55 SAN 15-07-2014, proced. 119/2014.

56 SAN 24-02-2014, proced. 493/2013.

57 SAN 18-12-2012, proced. 257/2012.

58 TSJ C.Valenciana 14-12-12, Proc 14/12; AN 28-9-12, Proc 152/12; SAN 30-9-13, Proc 225/13; TSJ Málaga 23-5-13, Proc 4/13 y STS 20-10-2015, rec. 272/2014.

59 TSJ Galicia 21-12-11, Rec 4102/11EDJ 315819; AN 18-12-12, Rec 257/12EDJ 273408.

60 STSJ Madrid 7-10-2014, rec. 515/2014.

${ }^{61}$ STSJ Cantabria 27-04-2013, rec. 468/13.

62 STSJ País Vasco 15-09-2015, rec. 13/15.

63 STS 25-02-2015, rec.74/2014 y SAN 26-10-2015, proced. 232/2015.

64 STSJ Sevilla 16-07-2015, rec. 2059/14.

65 SAN 26-10-2015, rec. 232/2015.

66 STS 25-06-2014, rec. 165/13 y 25-02-2014, rec. 74/14. 
colectivo, así como la documentación fiscal o contable acreditativa de los ingresos ordinarios o ventas registrados en los mismos trimestres del ańo inmediatamente anterior, lo cual constituye presupuesto constitutivo para la justificación de la medida ${ }^{67}$. - Para ello, podrá utilizarse cifra de negocios del art. 35.2 Código Comercio, integrada en la cuenta de pérdidas y ganancias ${ }^{68}$. - Esta documentación, que debe entregarse al inicio del período de consultas ${ }^{69}$, se relaciona directamente con la información, contenida en el art. 64.2.a y b ET, habiéndose admitido la justeza del despido, cuando se acreditan reducciones de ingresos y ventas en los últimos trimestres y la actividad de la empresa se ha reducido por encima del número de extinciones ${ }^{70}$, siendo exigible que esa disminución lo sea durante tres trimestres consecutivos y por comparación de los mismos con sus correlativos de la anualidad anterior, que no se satisface porque la situación sólo se refería a un área del hotel ${ }^{71}$, habiéndose entendido, en todo caso, que la reducción de ingresos o ventas no tiene que estar referida obligatoriamente a los tres últimos trimestres ${ }^{72}$, sin que quepa presumir que se va a producir disminución de ingresos o ventas por la simple modificación de los precios públicos del servicio $^{73}$.

La reducción de ingresos y ventas durante tres trimestres consecutivos no debe aplicarse mecánicamente, puesto que puede existir situación económica negativa, aunque no se alcance dicho período, porque la norma permite que la disminución se produzca en período inferior, siendo posible, así mismo, que la reducción durante tres trimestres consecutivos no justifique por sí sola el despido $^{74}$. - Se ha admitido la concurrencia de causa cuando se acredita importante reducción de ingresos y ventas tres trimestres consecutivos, que no tienen que ser los últimos ${ }^{75}$, pero si deben arrojar disminuciones en cada uno de los trimestres comparados ${ }^{76}$, así como reducciones de ingresos durante 5 trimestre consecutivos ${ }^{77}$, o 6 trimestres consecutivos ${ }^{78}$, o reducción de ingre-

67 SAN 11-03-2013, proced. 381/2012.

68 SAN 21-11-2012, proced. 167/2012.

69 SAN 11-10-2013, proced. 261/2013.

70 SAN 11-03-2013, proced. 281/2012.

71 STSJ Valladolid 23-02-2015, rec. 2020/2014.

72 STS 21-05-2014, rec. 182/2013 y STSJ Madrid 7-10-2014, rec. 515/2014.

73 STSJ Cantabria 27-03-2013, rec. 139/2013.

74 Aurelio Desdentado, obra citada, subraya que lo que dice la norma es que si la disminución tiene una duración de tres trimestres en determinadas condiciones se entenderá que es persistente, pero queda abierta la posibilidad de acreditar la persistencia de una disminución de duración inferior y, desde luego, una situación negativa puede acreditarse al margen de esa duración temporal de los hechos que la determinan, sin que quepa tampoco un automatismo positivo, cuando la reducción de ingresos o ventas es ínfima.

75 STS 21-05-2014, rec. 182/2013.

76 STS 28-01-2014, rec. 46/13 y SAN 10-11-2015, proced. 248/15.

77 SAN 18-01-2016, proced. 311/2015.

78 STS 28-01-2014, rec. 46/2013. 
sos reiterada ${ }^{79}$, concurriendo, en cualquier caso, cuando la reducción de ingresos y ventas en los tres últimos trimestres se asocia con una fuerte previsión de pérdidas ${ }^{80}$.

En definitiva, no es preciso que concurran al tiempo la disminución de ingresos y ventas, admitiéndose la concurrencia de causa, aunque las ventas hayan mejorado, cuando se produce reducción de ingresos, puesto que permite constatar rentabilidad negativa ${ }^{81}$. - La referencia a tres trimestres consecutivos, para acreditar la persistencia, pretende esquivar la estacionalidad, que se produce en muchas actividades productivas, no siendo lo mismo, cuando se contemplan períodos en los que se realizan promociones o rebajas ${ }^{82}$. Concurre, así mismo, cuando se ha producido reducción de ventas durante tres ejercicios, que han provocado, además, pérdidas en el último ańo con la consiguiente declaración de concurso ${ }^{83}$.

No es necesario esperar a la actualización de las pérdidas, o a su previsión, por lo que la empresa puede invocarla eficazmente aunque sus resultados sean positivos, puesto que una merma importante y continuada de ingresos o ventas socavará inexorablemente aquellos de no tomarse las medidas adecuadas ${ }^{84}$. En todo caso, la disminución de ventas, asociada a pérdidas actualizadas, constituye causa económica negativa ${ }^{85}$, especialmente, si se adiciona al descenso de ventas, la concurrencia de pérdidas cuantiosas ${ }^{86}$. El descenso de ingresos por reducción de ventas y el consiguiente descenso del volumen de negocio, constituye causa suficiente ${ }^{87}$, al igual que la reducción de ingresos durante seis trimestres consecutivos $^{88}$, justificándose también cuando la reducción de ingresos trae causa en la pérdida de una subvención ${ }^{89}$, o la reducción de ingresos, anudada a un volumen muy alto de gastos ${ }^{90}$ y también la reducción de ingresos durante cuatro trimestres consecutivos ${ }^{91}$.

Puede asociarse con causas productivas, cuando la reducción de ingresos provoca pérdidas cuantiosas y obliga a ajustar la actividad productiva de la em-

79 STSJ Navarra 24-03-2014, rec. 220/13.

80 SAN 18-12-2012, proced. 217/12; STS 28-01-2014, rec. 46/13; STS 17-11-2014, rec. 79/14 y STS 29-12-2014, rec. 83/14); STSJ Murcia 3-07-2015, rec. 148715 y STSJ Asturias 6-11-2015, rec. $1969 / 15$.

81 STS 20-09-2013, rec. 11/13 y STSJ Madrid 13-01-2014, rec. 1263/13.

82 TSJ Valladolid 4-12-13, Rec 1623/13.

83 STSJ Las Palmas 27-08-2015, rec. 545/15.

84 SAN 11-3-13, Proc 381/12 y STSJ Navarra 24-03-2014, rec. 220/13.

85 STS 21-04-2015, rec. 357/14.

86 STSJ Cataluña 23-12-2014, rec. 5569/14.

87 STSJ País Vasco 30-09-2014, rec. 1703/14.

88 STS 28-01-2014, rec. 46/13.

89 STS 18-02-2014, rec. 74/13.

90 STSJ Madrid 30-05-2014, rec. 118/14.

91 STSJ Madrid 18-11-2014, rec. 271/14. 
presa $^{92}$, descenso de ventas y anulación de pedidos ${ }^{93}$, y también cuando se acreditan pérdidas millonarias actualizadas, causadas por la reducción de ventas ${ }^{94}$, junto con la pérdida del principal cliente, anudada a pérdidas ${ }^{95}$. - Aunque la norma solo enfatiza el factor temporal, se actualizará normalmente cuando las reducciones sean significativas ${ }^{96}$, admitiéndose la concurrencia cuando es de tres años consecutivos ${ }^{97}$ y también cuando se acredite reducción de facturación, que ha supuesto pérdidas continuadas y fuerte endeudamiento ${ }^{98}$, así como pérdidas originadas por la reducción del negocio ${ }^{99}$.

\section{Empresa encuadrada en grupo de empresas}

\subsection{Grupo mercantil}

$\mathrm{El}$ art. 4.5 del Reglamento distingue qué documentación deben presen$\operatorname{tar}$ las empresas, que formen parte de un grupo de empresas mercantil, para la promoción de un despido colectivo por causas económicas. - Así, cuando el grupo mercantil esté obligado a consolidar cuentas anuales, siempre que la sociedad dominante tenga su domicilio en España, deberán acompañarse las cuentas anuales e informe de gestión consolidados de la sociedad dominante del grupo debidamente auditadas, en el caso de empresas obligadas a realizar auditorias, durante el período seńalado en el apartado 2, siempre que existan saldos deudores o acreedores con la empresa que inicia el procedimiento. -Conviene precisar aquí, que el art. 8 RDL 1/2010 aplica el derecho español a las sociedades domiciliadas en España, fuere cual fuere su lugar de constitución, entendiéndose por domicilio, a tenor con lo dispuesto en el art. 9 de la norma antes dicha, el lugar en que se halle el centro de su efectiva administración y dirección, o en el que radique su principal establecimiento o explotación o, en su caso, cuando su principal establecimiento o explotación radique dentro del territorio español deberán tener su domicilio en España, por lo que el legislador español ha optado por el domicilio real frente al domicilio formal. - Debe subrayarse también, que si no se aportasen las cuentas consolidadas, porque la sociedad dominante no esté domiciliada en España, se liquidará la finalidad de la consolidación de cuentas, que busca precisamente garantizar la transparencia de la gestión empresarial para los acreedores y socios, quienes

92 STS 25-09-2013, rec. 3/13.

93 STSJ Aragón 27-05-2015, rec. 300/15.

94 SAN 18-01-16, proced. 311/15.

95 STS 29-09-2015, rec. 145/2014.

96 TSJ Madrid 16-12-13, Rec 1242/13; TSJ Valladolid 19-6-13, Proc 10/13; AN 18-12-12, Proc 257/12.

97 STS Castilla la Mancha 16-12-2013, rec. 116/13 y STSJ Burgos 15-10-2014, rec. 692/14.

98 STSJ Madrid 7-10-2014, rec. 216/14.

99 STS 25-02-2015, rec. 145/14. 
tienen derecho obtener de la sociedad obligada a formular las cuentas anuales consolidadas los documentos sometidos a la aprobación de la Junta, así como el informe de gestión del grupo y el informe de los auditores (art. 42.5 C.Co.), por lo que parece razonable la aportación de las cuentas consolidadas, puesto que los representantes de los trabajadores tienen derecho a la misma información que los socios (art. 64.4.a ET) y obligaría a despejar, si no se entregara, si dicha información es pertinente o no lo es.

Así pues, cuando la empresa promotora forme parte de un grupo mercantil, deberá identificar quien ostenta la condición de sociedad dominante, así como si está obligada a consolidar cuentas, en cuyo caso deberá aportar las cuentas consolidadas ${ }^{100}$ o no lo está (art. 43 C.Co.), lo cual le eximirá del deber de aportar las cuentas consolidadas ${ }^{101}$. - Si no estuviera obligada, deberá identificar si las demás empresas del grupo están domiciliadas en España, se dedican a la misma actividad y si existen o no saldos acreedores o deudores entre ellas, aunque se ha defendido que la carga de la prueba de dichos extremos compete al demandante ${ }^{102}$, habiéndose mantenido que para admitir este defecto informativo, los demandantes debían haber acreditado que las empresas tenían su domicilio social en Espańa; que tenían la misma actividad o pertenezcan al mismo sector de actividad, y que entre las empresas del grupo hubiera saldos deudores y acreedores y solo se acredita el último requisito y además durante el período de consultas, no se solicitó esta documentación ${ }^{103}$, pero dicha exigencia se antoja desproporcionada, puesto que la empresa promotora tendrá mucha más facilidad probatoria que los representantes de los trabajadores sobre dichos extremos, debiendo aplicarse lo dispuesto en el art. 217.6 LEC.

Si no existiera obligación de formular cuentas consolidadas, además de la documentación económica de la empresa que inicia el procedimiento a que se ha hecho referencia, deberán acompañarse las de las demás empresas del grupo debidamente auditadas, en el caso de empresas obligadas a realizar auditorias, siempre que dichas empresas tengan su domicilio social en España, tengan la misma actividad o pertenezcan al mismo sector de actividad y tengan saldos deudores o acreedores con la empresa que inicia el procedimiento ), en cuyo caso la empresa promotora deberá a aportar todas las cuentas de las demás empresas del grupo ${ }^{104}$. - No obstante, la concurrencia de pérdidas en empresa, in-

100 STSJ Navarra 13-12-2013, rec. 226/2013; STSJ Valladolid 17-04-2013, rec. 4/2013; SAN 26-01-2015, proced. 205/2014 y 15-04-2015, proced. $180 / 2013$ y STS 25-03-2015, rec. $245 / 2014$ y $20-05-2015$, rec. $290 / 2014$.

101 STSJ Madrid 2-02-2015, rec. 872/2014.

102 STSJ Castilla la Mancha 9-01-2014, rec. 918/2013.

103 STSJ Madrid 11-11-2014, rec. 384/2014.

104 STSJ Navarra 13-12-2013, proced. 226/2013 y STSJ Madrid 29-01-2014, rec. $1652 / 2013$. 
tegrada en grupo mercantil, no extenderá la responsabilidad a las demás empresas del grupo ${ }^{105}$, pero se declarará nula la medida extintiva, condenando solidariamente a todas las codemandadas, si la empleadora ha incumplido la obligación documental de presentar cuentas consolidadas de las empresas integran ${ }^{106}$ es del grupo, pues junto con la memoria explicativa, no ha presentado las cuentas anuales de los últimos ejercicios completos, debidamente auditadas, firmadas por los administradores o representantes de la empresa ${ }^{107}$.

\subsection{Grupo a efectos laborales}

Por el contrario, si la empresa se encuadra en grupo a efectos laborales, se extenderá la responsabilidad a todas las empresas del grupo ${ }^{108}$, porque todas ellas son propiamente el empresario real ${ }^{109}$, lo que no sucederá cuando la empresa promotora entrega a la representación de los trabajadores con la comunicación inicial del período de consultas toda la documentación precisa de la misma, y además de toda la documentación económica relativa al resto de las empresas codemandadas, que acredita la inexistencia de las notas exigidas para que el grupo lo sea a efectos laborales ${ }^{110}$.

Cuando la empresa promotora del despido colectivo esté encuadrada en un grupo de empresas a efectos laborales, entendiéndose como tal aquel en que concurra confusión patrimonial, unidad de caja, utilización fraudulenta de la personalidad jurídica y uso abusivo de la dirección unitaria en perjuicio de los derechos de los trabajadores ${ }^{111}$, deberán aportarse las cuentas consolidadas, si es que era obligada dicha consolidación y, en su defecto las cuentas de todas las empresas del grupo, puesto que todas ellas ostentan la condición de empleadoras de los trabajadores ${ }^{112}$.

\subsubsection{La concurrencia de confusión patrimonial}

Se ha admitido la concurrencia de confusión patrimonial, cuando se acredita un crédito de 1,7 MM euros no explicado y el abono de las nóminas de otra empresa por importe de $872.427,33$ euros $^{113}$, o cuando la empresa dominante que avala, sin ninguna contraprestación, las actividades de las demás

105 STS 28-01-2014, rec. 46/2013.

106 STS 25-06-2014, rec. 165/2013, confirma SAN 18-12-2012 y STS 18-03-2014, rec. $114 / 2013$.

107 STSJ Navarra 13-12-2013, rec. 226/2013 y STSJ Cataluña 30-09-2013, rec. 4/2013.

108 STS 29-01-2014, rec. 121/2013.

109 SAN 29-10-2015, proced. 240/2015.

110 STSJ Asturias 20-11-2013, rec. 48/2013.

111 Por todas STS 20-10-2015, rec. 272/2014.

112 STSJ Madrid 25-06-2012, proced. 21/2012; SAN 26-07-2012, proced. 124/2012; STS $25-$ 06-2014, rec. 165/2013, confirma SAN 18-12-2012 y STS 18-03-2014, rec. 114/2013.

113 STSJ Rioja 13-12-2013, rec. 236/2013. 
empresas del grupo ${ }^{114}$, o cuando se demuestra que las personas físicas se apropiaban de los beneficios sociales ${ }^{115}$, o cuando la mercantil propietaria de un hotel, que explota otra del mismo grupo, al que se considera laboral ${ }^{116}$. — Se ha admitido también la concurrencia de caja única, considerándose manifestación de confusión patrimonial, cuando una empresa centraliza la actividad administrativa de las demás y abona el salario a los trabajadores de todas ellas, que prestan indistintamente servicios para todas las empresas del grupo ${ }^{117}$. - También cuando existe un préstamo participativo irrecuperable e inútil para una empresa que carece de actividad y personal ${ }^{118}$. - Se ha defendido, del mismo modo, que no constituye una mera operación de aval, sino en todo un conjunto de diez operaciones hipotecarias constituidas sobre propiedades de dos de las empresas para garantizar obligaciones de otras entidades y dos hipotecas más a favor de la Hacienda Pública para garantizar deudas tributarias también de la una de las empresas, así como una serie de préstamos entre empresas del grupo y un préstamo de unas a otras, donde la primera aparece no como quien recibe de las otras empresas sino como quien presta, lo que demuestra que estamos en una circulación económica de doble sentido ${ }^{119}$, o cuando se demuestra falta de transparencia en las cuentas, que no ofrecen imagen real de la empresa, puesto que se vendió un inmueble a otra empresa y se objetó por la auditoria ${ }^{120}$. — También, concurre grupo de empresas a efectos laborales, cuando se acredita confusión patrimonial entre varias sociedades del grupo, quienes realizaron transferencias sin acogerse a los términos del mercado, existiendo, además, confusión de plantillas entre ellas ${ }^{121}$. - Se ha declarado que el despido fue nulo, por cuanto se trata de un grupo de empresas a efectos laborales, así como cesión ilegal de trabajadores, entendiendo que no cabe anular la sentencia, porque la prueba se inadmitiera por la Secretaria, por cuanto dicha decisión no generó indefensión a los demandados ${ }^{122}$ y también se ha admitido la concurrencia de grupo de empresas a efectos laborales, al acreditarse la apariencia externa, actuación unitaria en el mercado, confusión patrimonial. Se rechaza, sin embargo, el levantamiento del velo respecto de los $\operatorname{socios}^{123}$.

Por el contrario, no hay confusión patrimonial, aunque se compartan centros de trabajo, siempre que se acredite la inexistencia de prestación indiferen-

\footnotetext{
114 STSJ Madrid 27-01-2014, rec. 63/2014.

115 STS 29-01-2014, rec. 121/2013.

116 STSJ Madrid 31-01-2014, rec. 1845/2013.

117 STS 22-09-2014, rec. 314/2013.

118 STSJ Madrid 9-02-2015, rec. 896/2014.

119 STS 20-11-2014, rec. 73/2014.

120 STSJ Madrid 27-01-2014, rec. 1541/2013.

121 SAN 2-06-2015, proced. 5/2015.

122 STS 16-06-2015, rec. 324/14.

123 STS 17-07-2015, rec. 312/14.
} 
ciada y se abonen los costos de manera diferenciada y transparente ${ }^{124}$, ni desestima dicha pretensión, puesto que la relación entre ambas mercantiles, en la que una es tenedora de acciones y propietaria de los inmuebles, mientras que la otra realiza la actividad productiva, está perfectamente documentada, lo cual permite concluir que se trata de empresas diferenciadas, no habiéndose acreditado la concurrencia de caja única ${ }^{125}$. - También se descarta la concurrencia de grupo de empresas, por cuanto no concurrían las notas exigidas por la jurisprudencia, aunque se concluye que no concurren causas económicas, por cuanto la auditoria de cuentas, solicitada por los demandantes, no se practicó por sus autores, sino por el administrador concursal, por lo que puede valorarse conforme a los cánones de la sana crítica, dándose la circunstancia de que ni se aportó el período de consultas, ni se registro en el plazo exigido legalmente, descartándose valor probatorio, por cuanto el tribunal de instancia no le otorgó poder de convicción ${ }^{126}$

Se ha descartado la confusión patrimonial, aunque las empresas del grupo se financian mediante el sistema de cash pooling, que ha sido validado por la doctrina civil (SAP Madrid 27-01-2014 y SAP Barcelona 25-10-2013) salvo en supuestos de descapitalización, por cuanto las operaciones estaban plenamente documentadas y permitían deslindar las realizadas por unas u otras empresas ${ }^{127}$. - Por el contrario, si se acredita la promiscuidad patrimonial, mediante la utilización del cash pooling, se entenderá que concurre grupo a efectos laborales ${ }^{128}$. -El cash pooling no comporta mecánicamente la concurrencia de caja única ${ }^{129}$, por cuanto la existencia de unidad de caja obliga a acreditar el descontrol financiero $^{130}$, habiéndose entendido que el cash pooling en el que está claramente deslindada la contabilidad y patrimonio de cada empresa excluye la responsabilidad solidaria laboral, por cuanto el cash pooling entre empresas de un mismo grupo produce una situación de caja única pero no determina necesariamente una confusión de patrimonios porque los ingresos y salidas de la cuenta centralizada están perfectamente documentados y diferenciados por empresas ${ }^{131}$. - También concurre confusión patrimonial cuando las mercantiles se fían o prestan entre sí, sin documentar dichas operaciones, ni retribuirlas en condiciones de mercado, o cuando se remiten facturas sin detallar los conceptos facturados, lo que no sucede con las remitidas a sus clientes y se constata la existencia de un prés-

124 SAN 30-09-2013, proced. 225/2013 y 23-12-2013, proced. 330/2013.

125 STS 24-09-2015, rec. 309/2014.

126 STS 20-05-2015, rec. 251/2014.

127 SAN 20-01-2014, proced. 256 y $257 / 2013$.

128 SAN 26-07-2012, proced. 91/2012 y 25-02-2013, proced. 324/2013 y STSJ Madrid 4-122013, rec. $1608 / 2013$.

129 Raquel Serrano Olivares. - El contrato de cash pooling.

130 STSJ Comunidad Valenciana 17-11-2010 y 2-03-2010, rec. 3351/2009 y 740/2010.

131 STS 28-01-2014, rec. 16/2013; SAN 20-01-2014, proced. 6 y 7/2014 y 12-06-2014, proced. 1082014. 
tamo inexplicado, cuando la empresa ya atravesaba graves dificultades ${ }^{132}$, así como facturas que no acreditan respeto a las condiciones de mercado $^{133}$. - Se ha admitido, además, la concurrencia de grupo de empresas a efectos laborales, cuando no se acredita por la empresa, que los precios facturados por los servicios centralizados a las empresas del grupo se realizaran en términos de mercado $^{134}$.

Deberá tenerse, en cuenta, no obstante, que tanto los activos como los pasivos financieros deberán valorarse con arreglo a criterios razonables, entendiéndose como tales los propios de un mercado fiable (art. 38 bis C. Co) de manera que deberá acreditarse que las operaciones de cash pooling respetan los parámetros antes dichos, para evitar la emergencia de actos colusorios de la competencia, así como la promiscuidad patrimonial. - Hay que contar, del mismo modo, con el denominado "privilegio de grupo", que activa, en aplicación de lo dispuesto en el art. 101 del Tratado de funcionamiento de la Unión Europea, la presunción de que los actos colusorios de la competencia realizados por la empresa filial se produjeron a iniciativa de la empresa dominante ${ }^{135}$, entre otras muchas.

\subsubsection{Confusión de plantillas}

Se admite, cuando se acredita la existencia de plantilla única con transferencia permanente entre las diferentes empresas ${ }^{136}$. - Se ha considerado, a estos efectos, que la utilización por las empresas del grupo de trabajadores contratados y retribuidos por una de ellas, sin que las usuarias del servicio abonaran la retribución, constituye, en la práctica, una manifestación de confusión patrimonial, por cuanto la empresa que paga sus servicios se empobrece y se benefician las demás, que disfrutan de su trabajo sin título o contraprestación ${ }^{137}$. — También la prestación indistinta de servicios entre la empresa que ejecutó el despido colectivo y las empresas del grupo ${ }^{138}$, así como, cuando se demuestra la prestación indistinta entre las empresas del grupo, sin que se probara retribución alguna por la utilización del personal de unas y de otras ${ }^{139}$, o cuando se acredita prestación indistinta de servicios, acreditándose que uno de los trabajadores está de alta en ambas empresas ${ }^{140}$, así como el trasvase permanente de personal entre las empresas del grupo sin control alguno ${ }^{141}$.

\footnotetext{
132 STSJ Valladolid 8-01-2015, rec. 11/2014.

133 SAN 14-10-2015, proced. 30/2014.

34 SAN 14-10-2015, proced. 30/2014.

135 STSJUE 11-07-2013, asunto C-440/11.

136 STSJ Madrid 24-04-2011, rec. 4774/2000.

137 STSJ Granada 19-12-2012, rec. 2283/2012 y SAN 12-06-2014, proced. 108/2014.

138 STSJ Extremadura 21-03-2013, rec. 141/2013.

139 SAN 25-11-2014, proced. 157/2014.

140 STSJ Valladolid 8-01-2015, rec. 11/2014.

141 STSJ Madrid 28-01-2014, rec. 84/2014 y STSJ Madrid 9-02-2015, rec. 896/2015.
} 
Sucederá lo mismo, cuando se acredita la prestación indistinta, así como la confusión patrimonial ${ }^{142}$, concurriendo ambas circunstancias, cuando se demuestra la utilización de servicios trasversales, que implicaban dirección común y un número muy importante de trabajadores, sin probar que las transferencias se producían en términos de mercado ${ }^{143}$, concurriendo también confusión de plantillas, cuando se produce la "externalización de la dirección» ${ }^{144}$, o cuando se prueba que las empresas tienen en común toda la estructura directiva y administrativa, sin haber acreditado cómo hacen la imputación de sus costes y que las transacciones se contabilizan a precios de mercado, correspondiendo a las empresas la carga de la prueba en razón de su disponibilidad probatoria $^{145}$.

Por el contrario, no concurre confusión de plantillas, ni tampoco confusión patrimonial, entre Confederación y Federación Regional, aunque haya coordinación entre ellas ${ }^{146}$. - Se ha descartado también la confusión de plantillas, aunque se probó que un gerente de una empresa había sido destinado a otra empresa del grupo en septiembre de 2012, pese a lo cual continuó cobrando su nómina de la empresa anterior hasta diciembre de 2012 porque "dado la brevedad del periodo y el hecho de que afectase a una sola persona, (esta irregularidad) no resulta de entidad suficiente para tildar tal situación de prestación indiferenciada de servicios del personal a las dos empresas del grupo» ${ }^{147}$. - Se ha descartado, del mismo modo, aunque un número importante de trabajadores de la empresa dominante preste servicios trasversales para ambas empresas, por cuanto se facturaban dichas prestaciones, subrayándose especialmente la transparencia de dicho proceso para descartar la concurrencia de fraude de ley, que es constitutivo para la existencia de grupo de empresas a efectos laborales $^{148}$. - Tampoco cuando se demuestra contundentemente, que dos mercantiles en proceso de fusión mantienen su propia organización, por lo que el personal de cada empresa se mantiene en su propia empresa, sin perjuicio de una interactuación progresiva, justificada cumplidamente por la finalidad perseguida, que es la definitiva fusión de ambas mercantiles, lo cual permite descartar, sin mayores razonamientos, la concurrencia de confusión de plantillas, siendo irrelevante, que algunos trabajadores de una empresa (31 trabajadores) pasaran a otra, puesto que dicho traspaso, legítimo dentro del grupo mercantil, se efectuó de manera transparente, explicándose las razones para hacerlo en las reuniones referidas en el hecho probado quinto, lo que permite descar-

\footnotetext{
142 STSJ Madrid 28-03-2014, rec. 10/2014.

143 SAN 28-03-2014, proced. 499/2013.

144 SAN 20-01-2014, proced. 256/2013.

145 SAN 14-10-2015, proced. 30/2014.

146 STSJ Asturias 21-02-2014, rec. 146/2014.

147 STS 21-05-2014, rec. 182/2013.

148 STS 20-10-2011, rec. 272/2014.
} 
tar cualquier ocultación o actuación fraudulenta, que es requisito constitutivo para la existencia de "grupo patológico» ${ }^{149}$, o cuando la prestación de servicios sucesiva de algunos trabajadores no alcanzó entidad suficiente como para admitir la confusión de plantillas, no habiéndose acreditado confusión patrimonial ${ }^{150}$.

\subsubsection{Uso abusivo de la personalidad jurídica}

El uso o utilización abusiva de la personalidad jurídica, se asocia normalmente con conductas estratégicas, que ponen abusivamente en valor el interés del grupo frente al de las sociedades que lo forman, infracapitalización, transferencia de gastos y apropiación de beneficios, utilización abusiva de la personalidad jurídica ${ }^{151}$, que se manifiesta claramente cuando se acredita que la empresa fue creada artificiosamente por la Diputación Provincial ${ }^{152}$ y también cuando se prueba que la Comunidad Autónoma externaliza brigada de incendios, gestionada por mercantil pública que acredita su condición de empresa real ${ }^{153}$, o cuando se demuestra que las empresas públicas codemandadas estaban dirigidas por personal de una de ellas y tenían servicios trasversales muy relevantes, cuyo coste no se probó ajustado a mercado, se concluye la concurrencia de grupo de empresas a efectos laborales ${ }^{154}$. - Del mismo modo, empresa dirigida por trabajadores de otra empresa desde 2011 ${ }^{155}$, así como cuando se acredita la existencia de una dirección externalizada de empresa del grupo, que es absorbida posteriormente por la empresa dominante ${ }^{156}$.

Se ha entendido lícita, por el contrario, la constitución por la Diputación Provincial de una mercantil pública, cuyos únicos ingresos provenían de las subvenciones de la propia Diputación que, una vez suprimidas, habilitan el despido

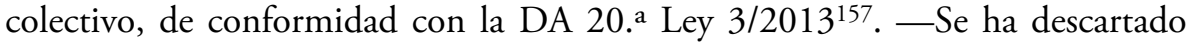
también la condición de empresario de Ayuntamiento que era un simple socio de la mercantil que promovió el despido colectivo ${ }^{158}$ ), manteniéndose el mismo criterio, cuando la empresa pública ejecutó una encomienda lícita, propuesta por la Consejería codemandada ${ }^{159}$.

\footnotetext{
149 SAN 18-01-2016, proced. 311/2015.

150 STS 29-09-2015, rec. $1 / 2015$.

151 Aurelio Desdentado, obra citada.

152 STSJ Valladolid 1-02-2012, rec. 2121/2011.

153 STSJ Galicia 20-06-2012, rec. 1451/2012.

154 SAN 28-03-2014, proced. 499/2013.

155 SAN 20-01-2014, proced. 257/2013.

156 SAN 20-01-2014, proced. 256/2013.

157 STS 18-02-2014, rec. 74/2013.

158 STSJ Cataluña 10-07-2013, rec. 21/2013.

159 STSJ Sevilla 25-10-2011, rec. 506/2011.
} 


\section{El debate inmediato: operaciones vinculadas y precios de mercado y requisitos para que prevalezca el interés del grupo frente al interés de las filiales y acreedores débiles, especialmente los trabajadores}

Las operaciones entre las empresas del grupo deben realizarse con arreglo al valor razonable, según la regla de valoración 21 del RD 1514/2007, de 16 de noviembre, que regula el Plan General de Contabilidad. -El art. 18 Ley 27/2014, del impuesto de sociedades prevé que las operaciones entre empresas vinculadas deberá valorarse con arreglo a su valor de mercado, entendiéndose como tal aquel que se habría acordado por personas o entidades independientes en condiciones de libre competencia.

Las reglas de valoración, que deberán estar documentadas, son las siguientes:

a) Método del precio libre comparable, por el que se compara el precio del bien o servicio en una operación entre personas o entidades vinculadas con el precio de un bien o servicio idéntico o de características similares en una operación entre personas o entidades independientes en circunstancias equiparables, efectuando, si fuera preciso, las correcciones necesarias para obtener la equivalencia y considerar las particularidades de la operación.

b) Método del coste incrementado, por el que se ańade al valor de adquisición o coste de producción del bien o servicio el margen habitual en operaciones idénticas o similares con personas o entidades independientes o, en su defecto, el margen que personas o entidades independientes aplican a operaciones equiparables, efectuando, si fuera preciso, las correcciones necesarias para obtener la equivalencia y considerar las particularidades de la operación.

c) Método del precio de reventa, por el que se sustrae del precio de venta de un bien o servicio el margen que aplica el propio revendedor en operaciones idénticas o similares con personas o entidades independientes o, en su defecto, el margen que personas o entidades independientes aplican a operaciones equiparables, efectuando, si fuera preciso, las correcciones necesarias para obtener la equivalencia y considerar las particularidades de la operación.

Cuando debido a la complejidad o a la información relativa a las operaciones no puedan aplicarse adecuadamente los métodos anteriores, se podrán aplicar los siguientes métodos para determinar el valor de mercado de la operación:

a) Método de la distribución del resultado, por el que se asigna a cada persona o entidad vinculada que realice de forma conjunta una o varias operaciones la parte del resultado común derivado de dicha operación 
u operaciones, en función de un criterio que refleje adecuadamente las condiciones que habrían suscrito personas o entidades independientes en circunstancias similares.

b) Método del margen neto del conjunto de operaciones, por el que se atribuye a las operaciones realizadas con una persona o entidad vinculada el resultado neto, calculado sobre costes, ventas o la magnitud que resulte más adecuada en función de las características de las operaciones, que el contribuyente o, en su caso, terceros habrían obtenido en operaciones idénticas o similares realizadas entre partes independientes, efectuando, cuando sea preciso, las correcciones necesarias para obtener la equivalencia y considerar las particularidades de las operaciones.

El art. 16.5 de la norma antes dicha regula específicamente la deducción de gastos en concepto de servicios entre entidades vinculadas, que deberán ajustarse a las reglas de valoración precedentes y las condiciona a la ventaja o utilidad que produzca en el destinatario de servicios comunes, estableciendo unos determinados requisitos:

a) Las personas o entidades participantes que suscriban el acuerdo deberán acceder a la propiedad u otro derecho que tenga similares consecuencias económicas sobre los activos o derechos que en su caso sean objeto de adquisición, producción o desarrollo como resultado del acuerdo.

b) La aportación de cada persona o entidad participante deberá tener en cuenta la previsión de utilidades o ventajas que cada uno de ellos espere obtener del acuerdo en atención a criterios de racionalidad.

c) El acuerdo deberá contemplar la variación de sus circunstancias o personas o entidades participantes, estableciendo los pagos compensatorios y ajustes que se estimen necesarios.

El acuerdo suscrito entre personas o entidades vinculadas deberá cumplir los requisitos que reglamentariamente se fijen.

El art. 16 RD 1777/2004, que regula el reglamento del impuesto de sociedades, determina el valor normal de mercado de las operaciones vinculadas, introduciendo el denominado "análisis de comparabilidad", mientras que el art. 17 regula los requisitos de los acuerdos de «reparto de costes». - Finalmente, los arts. 18 y 19 de la norma examinada establecen la obligación de documentación de las operaciones entre personas vinculadas y la obligación de documentación del grupo, denominado "cuaderno de transferencias», en cumplimiento del art. 18.3 Ley 27/2014, sobre el impuesto de sociedades, que se convertirá en documentación relevante, cuando se pretenda acreditar o desmentir la concurrencia de la nota de confusión patrimonial. —De hecho, el art. 19.f prevé que en la citada documentación contenga una descripción de la política 
del grupo en materia de precios de transferencia que incluya el método o métodos de fijación de los precios adoptado por el grupo, que justifique su adecuación al principio de libre competencia, mientras que el apartado h obliga a identificar los acuerdos de reparto de costes y contratos de prestación de servicios entre entidades del grupo, en cuanto afecten, directa o indirectamente, a las operaciones realizadas por el obligado tributario.

Entrará en juego, así mismo, el interés de grupo y su prevalencia respecto al interés de sus filiales y consecuentemente a los acreedores, especialmente los más débiles, como pueden ser los trabajadores, que obligará a examinar, caso por caso, si las operaciones vinculadas se justifican razonablemente o, por el contrario, acreditan confusión patrimonial. - Así, se ha considerado que no constituye confusión patrimonial "el mero hecho de que las empresas demandadas se hayan otorgado garantías en determinadas operaciones de crédito o que los vehiculos de algunas de ellas se hayan depositado en locales de otras, lo que puede entrar dentro de la actuación del interés de grupo, sin que conste la existencia de un perjuicio relevante a otros efectos" ${ }^{160}$.

Conviene precisar aquí, que el acceso a dicha información no puede basarse en meras suposiciones o dudas, puesto que los libros y documentos de la empresa son secretos, a tenor con lo dispuesto en el art. 32.1 C.Co., de manera que su exhibición en los despidos colectivos, prevista en el apartado 2 de dicho artículo, no es mecánica, debiendo limitarse exclusivamente, a tenor con el apartado 3 del artículo reiterado, a los puntos que tengan relación con la cuestión de que se trate, de manera que los representantes de los trabajadores no estarán legitimados para solicitar ilimitadamente el acceso a los libros, correspondencia y demás documentos del empresario, entre los que se encuentra el cuaderno de transferencias, puesto que se trata de un documento estratégico de la empresa, que solo podrá reclamarse cuando se trate de examinar operaciones vinculadas concretas, en las que haya indicios razonables de que no se han realizado en condiciones de mercados ${ }^{161}$, lo cual obligará a asegurar, en todo caso, el debido deber de secreto. - Así, no se ha dado valor a un deterioro del fondo de comercio de más de $17 \mathrm{MM}$ euros, apoyándose en afirmaciones genéricas del auditor, quien se limitó a mencionar que se había efectuado con arreglo a criterios de mercado, ya que un deterioro tan relevante, que multiplicó las pérdidas de la empresa, exigirá precisar si el test de deterioro se han efectuado con arreglo a los métodos del Plan General de Contabilidad ${ }^{162}$.

Destacar finalmente que la carga de la prueba de que las operaciones vinculadas entre las empresas del grupo se han realizado en términos de mercado compete

\footnotetext{
160 STS de 24 de septiembre de 2013, rec. 2828/2012.

161 SAN 18-01-2016, proced. 311/2015.

162 SAN 11-11-2014, proced. 251/2014.
} 
a la empresa ${ }^{163}$, aunque la denuncia de dicha circunstancia debe alegarse necesariamente en el período de consultas, puesto que si no se hizo así, quebraría la exigencia de buena fe, alegarlo por vez primera en el acto del juicio ${ }^{164}$.

\section{La documentación complementaria y su relevancia}

Tal y como se anticipó más arriba, es práctica habitual que los representantes de los trabajadores soliciten documentación complementaria respecto de la prevista legal y reglamentariamente y constituye práctica común, que se rechace su aportación total o parcialmente por parte de sus empleadores, lo que ha provocado una fuerte conflictividad, puesto que si dicha documentación se revela pertinente, por lo que su falta de aportación impidió que el período de consultas alcanzase sus fines, la consecuencia sería la nulidad del despido. - Conviene precisar aquí, que la contabilidad de los empresarios es secreta (art. 32.1 C.Co.), pero también es verdad que los representantes de los trabajadores tienen derecho a la comunicación o reconocimiento de los libros, correspondencia y demás documentos de los empresarios, ya sea de oficio o a instancia de parte, en los procedimientos de regulación de empleo (art. 32.2 C.Co.), sin perjuicio del derecho de los empleadores a que se asegure el deber de sigilo, para lo cual está previsto, incluso, un procedimiento específico de conflicto colectivo (art. 153.3 LRJS).

La carga de la prueba de la pertinencia del documento corresponderá a los representantes de los trabajadores, quienes deberán justificar razonablemente ante el empresario la necesidad de acceder a la correspondiente documentación (SAN 4-04 y 20-05-2013 y 28-03-2014, proced. 66/2013; 108/2013 y 44/2014). - Tampoco será exigible que la empresa aporte documentación de la que no dispone, al ser inadmisible que elabore documentos inexistentes (SAN 11-11-2014, rec. 251/2014), pero si dispone de ellos, como podría suceder con las cuentas de cada uno de los centros de trabajo afectados, si sería documentación pertinente, cuando se discute sobre la viabilidad de cada uno de ellos (SAN 15-04-2015, proced. 180/2013).

En cualquier caso, convendría ser extremadamente prudente, cuando se niegue el acceso a los libros, especialmente al libro diario, cuando se discuta la certeza de operaciones concretas, así como el libro de Inventarios y Cuentas, en el que se transcribirán al menos trimestralmente con sumas y saldos los balances de comprobación, que deberían coincidir con las cuentas provisionales. -Especial mención, al cuaderno de transferencias, regulado en los arts. 18 y 19 del RD $1777 / 2004$, que regula el reglamento del impuesto de sociedades, que establecen la obligación de documentación de las operaciones entre personas vinculadas y

\footnotetext{
163 STSJ Valladolid 27-05-2015, rec. 1/2015 y SAN 14-10-2015, proced. 30/2014.

164 STS 20-10-2015, rec. 272/2014.
} 
la obligación de documentación del grupo, que podrá convertirse en documentación relevante, cuando se pretenda acreditar o desmentir la concurrencia de la nota de confusión patrimonial, puesto que el art. 16 de la norma citada exige que las operaciones vinculadas se realicen en términos de mercado, introduciendo el denominado «análisis de comparabilidad», mientras que el art. 17 regula los requisitos de los acuerdos de «reparto de costes».

En efecto, cuando se debata la certeza de las cuentas auditadas, no bastará con la simple utilización de reglas estereotipadas, como la afirmación de que las transferencias se ha realizado con arreglo a criterios de mercado, sino que tendrá que acreditarse que se han utilizado criterios de medición de general aceptación (SAN 28-03-2014, proced. 499/2013). - Así, no se ha dado valor a una deterioro del fondo de comercio de más de $17 \mathrm{MM}$ euros, apoyándose en afirmaciones genéricas del auditor, quien se limitó a mencionar que se había efectuado con arreglo a criterios de mercado, ya que un deterioro tan relevante, que multiplicó las pérdidas de la empresa, exigirá precisar si los test de deterioro se han efectuado con arreglo a los métodos del Plan General de Contabilidad (SAN 11-11-2014, proced. 251/2014). —Del mismo modo, si las cuentas no son fiables, porque expresan resultados contradictorios (SAN 13-01-2014, proced. 154/2013), o se acredita la concurrencia de contabilidad B, que no sería por si causa de nulidad, si se hubiera informado sobre la misma, la consecuencia inexorable será la nulidad del despido (STS 18-02-2014, rec. 42/2013). —Así, se ha defendido que el juicio de adecuación debe comprobar la existencia de las causas alegadas, su pertenencia al tipo legal descrito en el art. 51 ET, así como la idoneidad del análisis de la medida en términos de gestión empresarial y en este caso determina que las cuentas anuales aportadas por la empresa, pese a reflejar las pérdidas, no expresan la imagen real de la situación económica de la misma, con lo cual no concurren las causas económicas justificativas de la extinción (STSJ Madrid 27-01-2014, rec. 1543/2013).

Parece claro, por tanto, que la aportación de la información legal y reglamentaria no colma la obligación empresarial de garantizar la documentación pertinente, que deberá ampliarse siempre que los representantes de los trabajadores acrediten la necesidad de pruebas suplementarias, lo que debería atenderse con generosidad, puesto que están en juego intereses legítimos para sus representados, lo que deberá contrapesarse con las necesarias garantías de confidencialidad que, caso de incumplirse, deberían promover acciones para satisfacer los perjuicios causados.

\section{La prueba del efecto desencadenante de la causa y la pérdida de eficacia económica del contrato}

Como se anticipó más arriba, una vez probadas las causas, corresponderá al empresario acreditar qué efectos provocan sobre los contratos de trabajo, 
lo que le obligará a demostrar qué contratos han perdido eficacia económica. - La prueba de la pérdida de eficacia económica de los contratos obligará a relacionar las pérdidas con sus causas, junto con los costes del personal y el ahorro pretendido con la medida, así como el sobredimensionamiento de la plantilla debido a la incidencia del rendimiento y productividad de los trabajadores.

\subsection{Pérdidas actualizadas}

Si concurre causa económica, particularmente cuando se deba a pérdidas actualizadas, la carga de la prueba se simplifica, puesto que la relación de pérdidas con los costes de personal permitirá determinar qué contratos han perdido su fundamento económico, de manera que, probada la existencia de pérdidas millonarias y desmesuradamente crecientes en los dos últimos ejercicios e importantes valores negativos de rentabilidad bruta en entidad bancaria rescatada, queda acreditada la existencia estructural de 700 plazas sobrantes ${ }^{165}$ y también cuando se demuestran pérdidas de 696 miles de euros, unidas a una reducción de la cifra de negocio descendió un $16 \%$, y de un $8 \%$ de facturación, junto con unos gastos de personal del 5,2 \% de los ingresos, que es la mitad del margen de rentabilidad de la empresa, se justifica la extinción de 37 puestos de trabajo ${ }^{166}$, sin que sea necesario acreditar que las pérdidas sean cuantiosas, continuadas, y progresivas, siempre que demuestren que los contratos afectados han vaciado su contenido económico ${ }^{167}$.

En el mismo sentido, se ha declarado que, una vez acreditadas pérdidas por importe de 2.291.289 euros (2012); 3.753 .433 euros (2013) y 10.198.615 euros (2014) y probada una fuerte reducción de ventas, reducción de envíos, reducción de precio por envío, reducción de facturación por trabajador, e incremento de costes laborales, unidos a medidas de racionalización productiva, que han perdido eficacia económica una cuarta parte de los contratos ${ }^{168}$. - De la misma manera, si una empresa del transporte aéreo acredita una situación económica negativa, concretada en una fuerte multiplicación de pérdidas (508 MM euros en 2013 y 115 MM euros en el primer semestre 2014), así como causas productivas, manifestadas en la reducción geométrica de sus resultados de explotación, que arrojaron - 519 MM euros en 2013 y- 95 MM euros a 30-062014, junto con cifras negativas de todos sus indicadores básicos, se considera que 1.183 puestos de trabajo han perdido su eficacia, por cuanto la reducción de actividad de la empresa, concretada esencialmente en la reducción de sus ingresos por pasaje, que supone un $72 \%$ de sus ingresos totales, es del $20,8 \%$, ha

\footnotetext{
165 STS 18-07-2014, rec. 288/13.

166 STS 22-09-2014, rec. 27/2014.

167 SAN 26-04-2013, proced. 29/13.

168 SAN 10-11-2015, proced. 248/15.
} 
provocado una pérdidas millonarias en 2013 y los primeros seis meses de 2014, mientras que las extinciones solo alcanzan al 8,05\% de la plantilla, habiéndose acreditado que las medidas de incremento de la productividad permitirán acometer sin quebranto la actividad real de la empresa con la plantilla restante, que quedaría reducida a 16.279 trabajadores ${ }^{169}$. -Del mismo modo, si se demuestran pérdidas de $338 \mathrm{MM}$ euros desde 2009 a 2013, de las cuales $72 \mathrm{MM}$ euros se produjeron en 2013 y $12 \mathrm{MM}$ euros en el primer trimestre de 2014 sin que se haya remontado lo más mínimo en el primer trimestre de 2014, que arrojó unos resultados negativos de 12, $3 \mathrm{MM}$ euros, frente a los - 9, $7 \mathrm{MM}$ euros del primer trimestre de 2013, se considera razonable la extinción de 68 contratos de trabajo $^{170}$.

Se ha admitido también que, si la empresa ha tenido pérdidas importantes y sostenidas, que ascendieron a 32 millones de euros en los últimos cinco años y se demuestra que 70 puestos de trabajo no tienen actividad que realizar, procede confirmar el despido colectivo ${ }^{171}$, entendiéndose del mismo modo que, si los ingresos netos de explotación evolucionaron a 360.085 .068 en 2009; en 2010 a 356.847.876; en 2011 descienden a 179.115.824 y por último en 2012 a 61.520.029, se justifica sobradamente la pérdida de virtualidad económica de 379 contratos de trabajo ${ }^{172}$ y también cuando los resultados del ejercicio de enero a septiembre de 2012 - 730 millones y en el mismo período en 2013,1.113 millones de euros, justifica sobradamente que 42 contratos de trabajo han perdido su virtualidad económica ${ }^{173}$. - En la misma línea, acreditadas pérdidas de 69.558.000 euros, unida a una fuerte reducción de actividad en empresa fuertemente endeudada, justifica la necesidad de amortizar 370 puestos de trabajo ${ }^{174}$, o cuando se acredita que la disminución de ingresos en los tres últimos trimestres consecutivos provoca una disminución de actividad muy superior al número de extinciones ${ }^{175}$.

\subsection{Pérdidas previsibles}

Más complejo resultará acreditar la pérdida de eficacia económica de los contratos, cuando la situación económica negativa se apoye en pérdidas previsibles, por cuanto la previsión de pérdidas habrá de basarse en datos obtenidos a través de las cuentas anuales, de los datos del sector al que pertenece la empresa, de la evolución del mercado y de la posición de la empresa en el mismo o de cualesquiera otros que puedan acreditar esta previsión, que en ocasiones será

\footnotetext{
169 SAN 9-02-2014, proced. 241/14.

170 SAN 4-12-2014, proced. 247/14.

171 STS 25-03-2015, rec. 1969/15.

172 STS 20-05-2015, rec. 283/14.

173 STS 21-04-2015, rec. 241/2015.

174 STS 25-02-2015, rec. $145 / 2014$

175 SAN 11-03-2013, proced. 281/12 y STSJ Burgos 13-02-2014, rec. 8/14.
} 
perfectamente acreditable, cuando se demuestra que la empresa entrará inmediatamente en números rojos por la pérdida de los contratos principales que abastecían a la empresa ${ }^{176}$, o cuando se pruebe que, además de las pérdidas ya actualizadas, hay clara previsión de acumulación de mayores pérdidas ${ }^{177}$, así como cuando se prueba pérdidas en tres trimestres consecutivos, que anticipa la producción de pérdidas futuras ${ }^{178}$.

Así pues, aun cuando la empresa no haya actualizado pérdidas, concurrirá situación económica negativa, que permitirá visualizar qué contratos no serán necesarios, cuando se acredite una disminución creciente de la facturación ${ }^{179}$, o la pérdida de la contrata principal de la empresa ${ }^{180}$, o la pérdida del cliente principal $^{181}$, que se considera causa eficiente, aunque parte de los contratos con los clientes se hayan extinguido por iniciativa de la empresa, cuando se demuestra su inviabilidad económica ${ }^{182}$ y también cuando se acredite la previsión de reducción de ingresos, que provocarán lógicamente pérdidas previsibles ${ }^{183}$. - Por consiguiente, en estos supuestos deberá acreditarse qué volumen de plantilla será necesaria para atender a la demanda prevista en la nueva situación, lo que permitirá identificar el número de contratos cuya amortización se justifica por la sobrecapacidad productiva de la empresa ${ }^{184}$. - Concurrirá particularmente, cuando se acreditan reducciones de ingresos importantes en los tres últimos trimestres, unido a fuerte previsión de pérdidas ${ }^{185}$.

\subsection{Reducción de ingresos o ventas durante tres trimestres consecutivos}

Sucederá lo mismo, cuando la situación económica negativa derive de la reducción de ingresos o ventas durante tres trimestres consecutivos, puesto que se trata de un supuesto específico, que identifica un período de tiempo concreto, en el que la empresa tiene dificultades, que podrían ser estructurales, en cuyo caso la acreditación de la pérdida de eficacia económica de los contratos será fácilmente comprobable, lo que sucederá cuando se prueben pérdidas, motivadas por reducción de ingresos durante seis trimestres consecutivos, que avocan al cierre de la empresa ${ }^{186}$, o cuando se despide a 24 trabajadores sobre 53 una

\footnotetext{
176 SAN 30-09-2013, proced. 225/2013.

177 SAN 29-09-2012, proced. 152/2012. y STSJ Cantabria 27-04-2013, rec. 468/2013.

178 STSJ País Vasco 15-09-2015, rec. 13/2015.

179 SAN 18-12-12, rec 257/12.

180 STSJ Madrid 7-10-2014, rec. 515/2014.

181 SAN 26-10-2015, proced. 232/15.

182 STS 25-06-2014, rec. 165/2013.

183 STS 25-06-2014, rec. $165 / 13$ y 25-02-2014, rec. $74 / 14$.

184 STS 20-10-2015, rec. 272/2014.

185 SAN 18-12-2012, proced. 217/12; STS 28-01-2014, rec. 46/13; STS 17-11-2014, rec. 79/14 y STS 29-12-2014, rec. 83/14); STSJ Murcia 3-07-2015, rec. 148715 y STSJ Asturias 6-11-2015, rec. $1969 / 15$.

186 STS 28-01-2014, rec. 46/2013.
} 
vez acreditada una reducción geométrica de ventas, unida a una reducción de precios $^{187}$, así como de acreditarse que la disminución de ingresos en los tres últimos trimestres consecutivos provoca una disminución de actividad muy superior al número de extinciones ${ }^{188}$, o cuando se acredita fuerte reducción de ventas, que ha generado pérdidas que, a la postre, provocaron la declaración de concurso de acreedores ${ }^{189}$.

Para que opere esta causa no es necesario esperar a experimentar pérdidas, o a que exista previsión de que se van a sufrir, de manera que la empresa puede invocarla eficazmente aunque sus resultados sean positivos, puesto que una merma importante y continuada de ingresos (o ventas) socavará inexorablemente aquellos de no tomarse las medidas adecuadas ${ }^{190}$. En cualquier caso, la disminución de ventas, asociada a pérdidas actualizadas, constituye causa económica negativa $^{191}$, especialmente, si se adiciona al descenso de ventas, la concurrencia de pérdidas cuantiosas ${ }^{192}$. El descenso de ingresos por reducción de ventas y el consiguiente descenso del volumen de negocio, constituye causa suficiente ${ }^{193}$, al igual que la reducción de ingresos durante seis trimestres consecutivos ${ }^{194}$, justificándose también cuando la reducción de ingresos trae causa en la pérdida de una subvención ${ }^{195}$, o la reducción de ingresos, anudada a un volumen muy alto de gastos ${ }^{196}$ y también la reducción de ingresos durante cuatro trimestres consecutivos $^{197}$. - Será necesario probar, sin embargo, que sobredimensionamiento provoca en la plantilla la reducción de ingresos o ventas, lo que constituye carga probatoria asequible para la empresa ${ }^{198}$.

\section{La adecuación entre la intensidad de las causas y las extinciones contractuales}

Como se señaló más arriba, el hecho de que la empresa atreviese una situación económica negativa no basta por sí solo para legitimar el despido, cuya justificación en el supuesto de ser objeto de impugnación se tiene que realizar a través de tres pasos: a) acreditar la existencia de una situación económica nega-

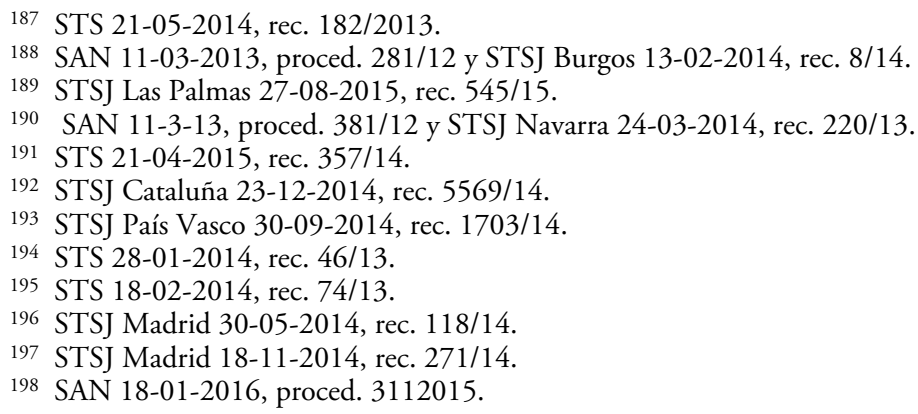


tiva; b) evidenciar que esa situación tiene la entidad necesaria como para afectar al volumen de empleo, haciendo precisa la reducción del número de puestos de trabajo o el cese total de la actividad; y, c) mostrar la adecuación de la medida extintiva para responder a esa necesidad ${ }^{199}$.

En efecto, aunque la definición y el tratamiento de las causas de despido colectivo y de despido objetivo por necesidades de la empresa sean comunes y compartidas, no significa que una misma causa, entendida como hecho subyacente a la decisión extintiva, pueda legitimar indistintamente el recurso a despidos colectivos o individuales/plurales, debiendo entenderse que los primeros están reservados a supuestos en los que las causas se manifiestan con singular intensidad y extensión y alcanzan por ello a un mayor número de trabajadores, puesto que el legislador ha optado por primar la utilización de medidas de flexibilidad interna para evitar la flexibilidad externa, que se convierte, de este modo, en la «ultima ratio» ${ }^{200}$.

La jurisprudencia ha establecido, que las extinciones colectivas deben superar un "test de proporcionalidad», que habría de desarrollarse en tres fases de «adecuación», entendiéndose como tal la idoneidad de la medida adoptada para conseguir el fin pretendido, lo que requiere identificar el fin perseguido y valorar si la medida tomada es razonable, esto es adecuada, idónea y apta para conseguir ese fin; de «necesidad», lo que obligará a demostrar que no existe otra más moderada para conseguir el mismo fin con igual eficacia y de "ponderación», que requerirá a examinar todos los derechos en juego y todas las circunstancias concurrentes, para acabar resolviendo si la medida es proporcionada y equilibrada por derivarse de ella más beneficios y ventajas para el interés general que perjuicios sobre otros bienes o valores en conflicto ${ }^{201}$.

Se ha defendido también a la necesidad de superación de un juicio de «razonabilidad», que tendría, a su vez, una triple proyección: 1).— Sobre la «existencia» de la causa tipificada legalmente como justificativa de la medida empresarial [modificativa o extintiva. 2)._- Sobre la "adecuación» de la medida adoptada, aunque en su abstracta consideración de que la medida se ajusta a los fines - legales - que se pretenden conseguir, bien de corregir o hacer frente - en mayor o menor grado- a la referida causa y 3).- Sobre la «racionalidad» propiamente dicha de la medida, entendiendo que este tercer peldaño de enjuiciamiento hace referencia a que han de excluirse por contrarias a Derecho las medidas empresariales carentes de elemental proporcionalidad ${ }^{202}$.

199 TS 25-6-14, EDJ 138299; AN 21-11-12, EDJ 250031; TSJ Madrid 9-3-13, proced. 18/13; STS 25-02-2015, rec. 74/14; STS 16-06-2015, rec. 283/14.

200 STS $16-07-2015$, rec. $180 / 14$.

201 STS 20-10-2015, rec. 272/2014, con citada de STS 15-04 y 25-06-2014, rec. 136 y $165 / 2013$.

202 STSS 20-10-2015, rec. 272/2014, con citada de STS 17-07-2014, rec. 32/2014. 
Consiguientemente, la empresa deberá acreditar que la intensidad de las causas justifica idónea, razonable y proporcionalmente la extinción de aquellos contratos, que hayan dejado de ser útiles económicamente ${ }^{203}$, de manera que ya no será necesario probar que las causas invocadas tengan entidad necesaria para afectar a la viabilidad de la empresa o a su capacidad de mantener el volumen de empleo, ni es preciso acreditar que la decisión extintiva permitirá preservar o favorecer su posición competitiva en el mercado, pero el empresario deberá acreditar que la causa se manifiesta con la intensidad suficiente como para dejar sin contenido económico los contratos que pretenda extinguir ${ }^{204}$, puesto que la nueva regulación del despido colectivo no puede ser interpretada en el sentido de que cualquier tipo de resultados económicos negativos, aún los de carácter mínimo, pueden viabilizar decisiones extintivas, pues una cosa es que la norma no exija ya que los resultados negativos sean tan adversos como para afectar a la viabilidad de la empresa o al volumen de empleo, y otra distinta que cualquier resultado negativo, al margen de su significación económica en función de las características de la empresa y de su trayectoria, legitime el recurso al despido, siendo exigible, por consiguiente, que la medida extintiva se adecue razonablemente a la intensidad de las causas ${ }^{205}$. - Por el contrario, cuando se acredite que el número de despedidos no es proporcional a la causa acreditada, se declarará la injustificación de la medida ${ }^{206}$, lo que sucederá, cuando se demuestre que la causa, en la que se funda la extinción, es la misma que motivó la suspensión de contratos ${ }^{207}$, salvo que se hubieran agravado suficientemente ${ }^{208}$, o cuando las pérdidas acreditadas no son tan intensas como para justificar el número de extinciones producidas ${ }^{209}$.

Así pues, no basta con acreditar la concurrencia de la situación económica negativa, sino que, en aplicación del art. 4 del Convenio 158 OIT, que impide aceptar que el control judicial del despido se limite a comprobar si concurren las circunstancias definidoras de una situación económica negativa, sino que sirve para determinar si concurre el nexo de razonabilidad entre lo pretendido - un determinado número de extinciones contractuales - y la causa desencadenante - una circunstancia económica y productiva ${ }^{210}$, de manera que cualquier tipo de resultado económico negativo, aún los de carácter mínimo, no viabilizan cualquier despido, porque una cosa es que la norma no exija ya que los resulta-

203 SAN 4-07-2013, proced. 169/2013; SAN 21-11-2013, proced. 322/2013; STS 29-09-2015, rec. $1 / 2015$.

204 SAN 9-02-2014, proced. 241/2014 y SAN 10-03-2014, proced. 285/13.

205 SAN 9-02-2014, proced. 241/14.

206 STS 26-03-2014, rec. 158/2013.

207 STS 17-07-2014, rec. 32/2014 y STS 22-10-2014, rec. 213/2014.

208 STS 24-09-2014, rec. 271/13; STS 16-06-2015, rec. 273/14.

209 STS 23-09-2014, rec. 231/13.

210 STS 17-07-2014, rec. 32/14 ; STS 16-06-2015, rec. 273/2014 y STS 25-02-2015, rec. $74 / 14$. 
dos negativos sean tan adversos como para afectar a la viabilidad de la empresa o al volumen de empleo, y otra distinta que cualquier resultado negativo, al margen de su significación económica en función de las características de la empresa y de su trayectoria, legitime el recurso al despido, siendo exigible, por consiguiente, que la medida extintiva se adecue razonablemente a la intensidad de las causas $^{211}$.

Ahora bien, la superación del test de "proporcionalidad» no significa que los tribunales puedan sustituir la gestión económica de la empresa ${ }^{212}$, puesto que no corresponde a los Tribunales fijar la precisa «idoneidad» de la medida a adoptar por el empresario ni tampoco censurar su "oportunidad» en términos de gestión empresarial ${ }^{213}$, ni tampoco fiscalizar si la gestión de la empresa ha sido o es la adecuada, lo que queda fuera de su ámbito de control, ni sustituir las medidas decididas por el empresario en el ejercicio de la libertad económica ${ }^{214}$, pero si deben pronunciarse sobre la concurrencia de razonabilidad, que se relaciona siempre con la proporcionalidad de la medida ${ }^{215}$, porque en tales supuestos la decisión adoptada por la empresa sería contraria al ejercicio del derecho con la exigible buena fe e incurriría en la prohibida conducta contraria a aquélla o en los también excluidos abuso del derecho o ejercicio antisocial del mismo» ${ }^{216}$. - En cualquier caso, el test de "proporcionalidad» exigirá ponderar todas las circunstancias concurrentes de manera que, si el número de extinciones fuera razonable y proporcionado procederá su confirmación, sin entrar en disquisiciones sobre la conveniencia de un porcentaje menor u otro tipo de medida menos agresiva, porque dicha elección corresponde al empresario y no al tribunal ${ }^{217}$.

\section{Causas técnicas, organizativas o de producción}

- Memoria explicativa de las causas, que acredite concurrencia de las causas

- La memoria deberá identificar la relación de funcionalidad entre las causas y la pérdida de eficacia económica de los contratos, con arreglo a técnicas de ponderación, entendiéndose como tales la razonabilidad y proporcionalidad de la medida (SAN 21-11-2012, proced. 167/2012).

211 SAN 9-02-2014, proced. 241/14.

212 SAN 19-11-2013, proced. 293/2013.

213 STS 20-10-2015, rec. 272/2014, con cita STS 27-01-2014, rec. 100/2013; STS 15-042014, rec. 136/2013 y STS 23-09-2014, rec. 231/2013.

214 SAN 28-9-12, Proc 152/12 y SAN 19-11-13, Proc 293/13.

215 STS 20-10-2015, rec. 272/2015, con cita STS 27-01-2014, rec. 1"/2013 y STS 26-032014, rec. $158 / 2013$.

216 STS $20-10-2015$, rec. $272 / 2014$, con cita STS $17-07-2014$, rec. 32/2014.

217 STS 20-10-2015, rec. 272/2015, con citad STS 23-09-2014, rec. 231/2013. 
- Informe técnico, cuya finalidad es acreditar la concurrencia de la causa y su adecuación con las medidas tomadas (SAN 24-10-2012 y STSJ Madrid 11-06-2012, proced. 22/2012 y SAN 4-02-2013, proced. 326/2012). - Si la causa es organizativa, se ha considerado pertinente que la empresa aportara informe técnico suficiente sobre su reorganización (SAN 12-06-2014, proced. 79/2014).

- Se ha declarado justificado el despido fundado en causas organizativas y productivas motivadas por la supresión del servicio de teleconcertación por haber decidido poner fin al mismo la empresa que lo había solicitado, dada la crisis del mercado publicitario a que pertenece la misma, sin que la empleadora tuviera actividad contratada con otras empresas ni perspectivas ciertas de obtenerla que permitiera la recolocación de los trabajadores del servicio en extinción, entendiéndose que no concurre mala fe empresarial (STS 21-04-2014, rec. 126/2013, confirma SAN 14-092012). 